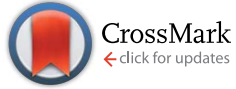

Cite this: RSC Adv., 2017, 7, 15439

Received 16th January 2017 Accepted 21st February 2017

DOI: $10.1039 / c 7 r a 00686 a$ rsc.li/rsc-advances

\section{Effect of fiber length and dispersion on properties of long glass fiber reinforced thermoplastic composites based on poly(butylene terephthalate)}

\begin{abstract}
Daohai Zhang, ${ }^{a b}$ Min He, ${ }^{a b}$ Shuhao Qin ${ }^{\star a b}$ and Jie $\mathrm{Yu}^{\star a b}$
Long glass fiber reinforced poly(butylene terephthalate) (LGF/PBT) composites with different original glass fiber lengths were prepared using a impregnation device designed by the authors. The influence of fiber length and fiber distribution on the properties of the LGF/PBT composites were studied. The results showed that the length of the residual glass fibers increased with the original glass fiber length increase of LGF/PBT composites. Scanning electron microscopy results indicated that the glass fibers of LGF/PBT composites (16 nm and $20 \mathrm{~mm}$ ) were unevenly dispersed and this is a phenomenon of their reunion in the resin matrix. Various rheological plots including viscosity curve, storage modulus, loss modulus, and loss angle, were used to characterization the rheological properties of the pristine matrix and the LGF/PBT composites. Dynamic mechanical thermal analysis results indicated that the storage and loss modulus of the LGF/PBT composites firstly increase and then decrease with original glass fiber length. The storage and loss modulus, glass transition temperatures of the pristine matrix and LGF/PBT composites increase with test frequencies increase. The activation energies of glass transition relaxation for the activation energies for loss tangent $(\tan \delta)$ and loss modulus $\left(E^{\prime \prime}\right)$ peaks were calculated. Furthermore, the glass transition relaxation determined from the $\tan \delta$ peaks were more reliable than using the $E^{\prime \prime}$ criterion. Differential scanning calorimetry analysis indicated that the crystallization temperature $\left(T_{c}\right)$, percentage crystallinity $\left(X_{c}\right)$ and melting point of the LGF/PBT composites firstly increased and then slightly decreased with the increase of the original glass fiber length. Thermogravimetry (TG) and differential thermal gravimetric analysis curves of the LGF/thermoplastic polyurethane (TPU)/PBT/polyethylene-butylacrylate-glycidyl methacrylate (PTW) composites were shifted to higher temperatures with the increase of the LGF content. Thermogravimetric analysis results showed that the TG curves of the LGF/TPU/PBT/PTW composites firstly shifted to higher temperatures and then shifted to lower temperatures as the original glass fiber length increased. The limiting oxygen values of the pristine matrix and LGF/PBT composites showed little change, which indicated that the effect of the original glass fiber length on the combustion behavior of LGF/PBT composites was not obvious. The tensile strength, notched Izod impact strength, flexural strength and modulus of the LGF/PBT composites firstly increase and then decrease with the original glass fiber length. When the original glass fiber length was $12 \mathrm{~mm}$, the mechanical properties of LGF/PBT composites were optimal.
\end{abstract}

\section{Introduction}

Long glass fiber (LGF) reinforced thermoplastic composites bridge the gap between short and continuous glass fiber reinforced thermoplastic composites, offering better mechanical properties than short glass fiber (SGF) reinforced thermoplastic composites. ${ }^{\mathbf{1 - 3}}$ The structural applications of SGF reinforced thermoplastic composites can be limited when compared with

${ }^{a}$ Department of Polymer Materials and Engineering, College of Materials and Metallurgy, Guizhou University, Guiyang 550025, China. E-mail: yujiegz@126.com; qinshuhao@126.com

${ }^{b}$ National Engineering Research Center for Compounding and Modification of Polymer Materials, Guiyang 550014, China the continuous glass fiber reinforced thermoplastic composites, because their mechanical properties are remarkably affected by the glass fiber size and orientation in the final glass fiber reinforced thermoplastic composite. ${ }^{4}$ At the same time, the shear forces inherent in the process lead to a significant reduction in glass fiber length during the injection molding of SGF reinforced thermoplastic composites, which causes the SGF reinforced thermoplastic composites ultimate strength decrease. ${ }^{5}$ LGF reinforced thermoplastic composites are usually prepared using a pultrusion process, in which continuous glass fibers with a polymer matrix surrounding them are pulled through a circular die. ${ }^{6,7}$ LGF reinforced thermoplastic composites exhibit excellent mechanical strength and modulus, impact resistance, fatigue resistance, and durability properties in 
which they are superior to the SGF reinforced thermoplastic composites. $^{8-10}$ Poly(butylene terephthalate) (PBT) is a semi crystalline thermoplastic resin, which has good electrical and mechanical performance including high strength, rigidity, toughness and chemical resistance to a wide range of chemicals, solvents, oils and greases. PBT has good dimensional stability, low moisture absorption, and powerful insulation resistance. ${ }^{\mathbf{8 1 1}}$ It is well known that the glass fiber length, orientation and distribution of LGF reinforced thermoplastic composites affects the performance of LGF reinforced thermoplastic composites. It was observed that considerable glass fiber damage occurred during the injection molding process for glass fiber reinforced thermoplastic composites, therefore, the average glass fiber length is reduced and the reinforcement efficiency for the glass fiber reinforced thermoplastic composites decreases. The researchers reported that the glass fiber orientation, glass fiber concentration, glass fiber length distribution and interfacial bond strength for the glass fiber reinforced thermoplastic composites were also responsible for the variation in the mechanical performance of the glass fiber reinforced thermoplastic composites. ${ }^{\mathbf{1 - 3 , 5 , 1 2}}$

In this paper, LGF/PBT composites with different original glass fiber lengths were prepared by using an impregnation device designed by the authors. The structure and morphology were characterized using scanning electron microscopy (SEM), dynamic mechanical analysis (DMA), differential scanning calorimetry (DSC), an advanced rheometric expansion system (ARES), and thermogravimetric analyses (TGA). The aim of this study was to clarify the influence of fiber length and distribution on the rheology characterization, dynamic mechanical, thermal and mechanical properties of the LGF/PBT composites and thus to develop a class of new high-performance LGF reinforced granulating composites with a different original glass fiber length based on that of the PBT matrix resins.

\section{Experimental}

\subsection{Materials}

PBT (grade L1082) was acquired from Sinopec Yizheng Chemical Co., Ltd., China. The flexibilizer [thermoplastic polyurethane (TPU), grade 2103-80AE, melt index $40 \mathrm{~g} / 10 \mathrm{~min}$ ] was supplied by Lubrizol Advanced Materials, Inc., OH, USA The glass fibers (grade 988), with a diameter of $10 \mu \mathrm{m}$, treated with a silane coupling agent in this research, were produced by Jushi Co., Ltd., China. The antioxidant was 1,3,5-trimethyl-2,4,6tris(3,5-di-tert-butyl-4-hydroxybenzyl) benzene (grade KY1330), which was obtained from Hangzhou Ha Rich Chemical Technology Co., Ltd., China.

\subsection{Preparation of the LGF/PBT composites}

The PBT, flexibilizer and antioxidant in a mass ratio of: $80: 20: 0.5$ were blended in a twin-screw extruder (Type TSE-40A/ 400-44-22, length/diameter $(L / D)=40, D=40 \mathrm{~mm}$, Coperion Keya Machinery Co., Ltd., Nanjing, China). The temperatures from the hopper to die at six different zones were $210{ }^{\circ} \mathrm{C}, 215^{\circ} \mathrm{C}, 220{ }^{\circ} \mathrm{C}$, $225{ }^{\circ} \mathrm{C}, 230^{\circ} \mathrm{C}$, and $235^{\circ} \mathrm{C}$, the screw speed was $200 \mathrm{rpm}$ and the impregnation temperature was $260{ }^{\circ} \mathrm{C}$. The composites were dried in a vacuum oven at $90{ }^{\circ} \mathrm{C}$ for $8 \mathrm{~h}$, and were then injection molded (Type CJ80M3V, Chen De Plastics Machinery Co., Ltd., Guangdong, China) at $245{ }^{\circ} \mathrm{C}$ into various specimens for testing and characterization. The melt-impregnation process of the LGF/PBT composites is displayed in Fig. 1.

\subsection{Glass fiber length analysis}

A FASEP 3E-ECO system (Emmeram Karg Industrietechnik, Germany) coupled with a scanner was used to determine the length of the residual glass fibers and their distribution in the specimens made from the LGF/PBT composites. To remove the matrix resins from the LGF/PBT composites, the injection molded specimens were first calcined in a furnace at a temperature about $700{ }^{\circ} \mathrm{C}$ for $6 \mathrm{~h}$. The glass fibers were then released from the matrix resins of LGF/PBT composites. Using the FASEP 3E-ECO system, the dispersed glass fibers were counted and measured to achieve the length of the residual glass fibers and their distribution. The number average length $\left(\overline{L_{n}}\right)$ could be calculated using the following equation:

$$
\overline{L_{n}}=\frac{\sum i N i L i}{\sum i N i}
$$

where, $N$ is statistical glass fiber number.

\subsection{Scanning electron microscopy (SEM) analysis}

The glass fibers dispersed and distributed in the matrix resins of the LGF/PBT composites were observed using SEM. The fracture surfaces of the samples were sputter coated with a gold layer before examination, and the micrographs of the morphology of LGF/PBT composites were obtained at magnifications of $1000 \times$ using a Quanta 250 SEM (FEI, USA) with an accelerating voltage of $25 \mathrm{kV}$.

\subsection{Rheology analysis}

Rheological measurements were performed using an ARES advanced rheometric expansion system (TA Instruments, USA) using parallel plates. The measurements were conducted at $240{ }^{\circ} \mathrm{C}$. The samples were loaded onto the bottom plate of the instrument and allowed to melt. To maintain a similar thermal history, each sample was heated for $4 \mathrm{~min}$ in the rheometer before testing. All the tests were kept with about a $1.0 \mathrm{~mm}$ gap between them. The frequency sweeps at $240{ }^{\circ} \mathrm{C}$ were performed in the frequency range of $0.05-500 \mathrm{rad} \mathrm{s}^{-1}$ in the linearity

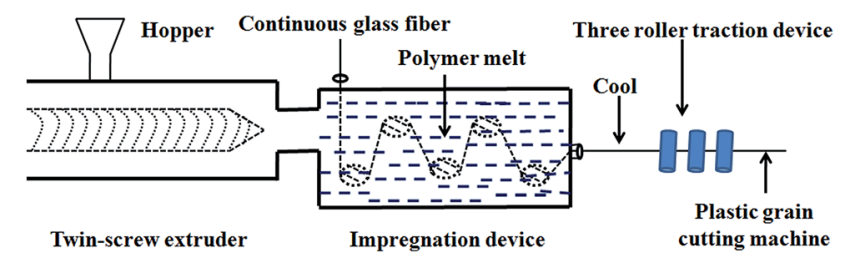

Fig. 1 The melt-impregnation process of the LGF (40\%)/PBT composites. 
region. A strain of $1 \%$ was used, which was in the linear viscoelastic region for all samples.

\subsection{Dynamic mechanical analysis (DMA) testing}

The DMA was performed on a Q800 DMA (TA Instruments, USA). The measurements were carried out at 1, 5, 20, 30 and $50 \mathrm{~Hz}$ under a heating rate of $2{ }^{\circ} \mathrm{C} \min ^{-1}$. The temperature range was from $-120{ }^{\circ} \mathrm{C}$ to $120{ }^{\circ} \mathrm{C}$. The low temperature measurements were performed in a stream of dry air cooled with liquid nitrogen $\left(\mathrm{N}_{2}\right)$, and the high temperature measurements were carried out in a stream of dry $\mathrm{N}_{2}$.

\subsection{Differential scanning calorimetry (DSC) analysis}

The thermal properties of all LGF/PBT composites as well as their composites with different original glass fiber lengths were studied using a Q10 DSC (TA Instruments). All the measurements were carried out in a $\mathrm{N}_{2}$ atmosphere. The samples were first heated to $250{ }^{\circ} \mathrm{C}$ and held for $5 \mathrm{~min}$ at this temperature to eliminate possible thermomechanical histories. Then, they were cooled to room temperature and again heated to $250{ }^{\circ} \mathrm{C}$ at a constant rate of $10{ }^{\circ} \mathrm{C} \mathrm{min}^{-1}$. The crystallization $\left(T_{\mathrm{c}}\right)$ and melting $\left(T_{\mathrm{m}}\right)$ temperatures were determined from the cooling and heating thermograms, respectively. The degree of crystallinity $\left(X_{\mathrm{c}}\right)$ of the composites was determined from the area under the exothermic crystallization peak in the cooling cycle:

$$
X_{\mathrm{c}}=\frac{\Delta H_{\mathrm{m}}}{(1-X) \Delta H_{\mathrm{m}}^{\mathrm{o}}} \times 100 \%
$$

where, $\Delta H_{\mathrm{m}}$ is the crystallization enthalpy of the samples $\left(\mathrm{J} \mathrm{g}^{-1}\right)$, $\Delta H_{\mathrm{m}}^{\mathrm{o}}$ is the enthalpy value of melting of a $100 \%$ crystalline form of PBT, and $X$ is the weight fraction of the filler.

\subsection{Thermogravimetric analysis (TGA)}

The TGA of the pristine matrix and the LGF/PBT composites was performed using a Q50 thermogravimetric analyzer (TA Instruments, USA) under a $\mathrm{N}_{2}$ flow with a flow rate of $40 \mathrm{ml} \mathrm{min}^{-1}$ in a temperature range of ambient to $650^{\circ} \mathrm{C}$ with a heating rate of $20^{\circ} \mathrm{C} \mathrm{min}^{-1}$. Each sample used in this test was $8-10 \mathrm{mg}$.

\subsection{Limiting oxygen index (LOI)}

The LOI values for the pristine matrix and the LGF/PBT composites were obtained using a JF-3 LOI instrument (Jiangning Analytical Instrument Factory, Nanjing, China) on sheets $100 \mathrm{~mm} \times 10 \mathrm{~mm} \times 4 \mathrm{~mm}$ according to the standard oxygen index test (ASTM D2863). The LOI value was calculated using the following equation:

$$
\mathrm{LOI}=\left[\mathrm{O}_{2}\right] /\left(\left[\mathrm{O}_{2}\right]+\left[\mathrm{N}_{2}\right]\right) \times 100 \%
$$

where $\left[\mathrm{O}_{2}\right]$ and $\left[\mathrm{N}_{2}\right]$ are the concentrations of oxygen and nitrogen, respectively.

\subsection{Mechanical properties testing}

The tensile and bending strengths were measured using a WDW-10C universal material testing machine (Shanghai
Hualong Testing Instrument Co., Ltd., China). The impact strength was measured using a ZBC-4B LCD type plastic pendulum impact testing machine (Shenzhen Xinsansi Measurement Technology Co., Ltd., China). All mechanical tests were performed at the room temperature $\left(25 \pm 2{ }^{\circ} \mathrm{C}\right)$.

\section{Results and discussion}

\subsection{The length of residual glass fibers of LGF/PBT composites}

There is no doubt that the length of the residual glass fibers is considered to be a critical factor for determining the reinforcement effect of the resulting composites as a result of the application of this LGF reinforced thermoplastic composite processing technique. Therefore, it is of great significance to understand how the length of the residual glass fibers and the glass fibers' distribution vary within the injection molded specimens of the LGF/PBT composites. Fig. 2 shows some representative distribution charts for the length of residual glass fibers within the injection molded specimens, and the corresponding optical micrographs are presented as insets. Furthermore, the number average glass fiber lengths were determined using the glass fiber length analysis software that was part of the FASEP system and are also summarized. The number average glass fiber length of LGF/PBT composites $(4,8$, 12,16 and $20 \mathrm{~mm}$ ) was $2.48,2.97,3.46,3.89$ and $4.17 \mathrm{~mm}$, respectively. The results of Tan $e t$ al. ${ }^{13}$ showed that the average glass fiber length of LGF reinforced thermoplastic polycarbonate/PBT alloys was from 2.55 to $2.88 \mathrm{~mm}$. However, the residual glass fiber length of the SGF reinforced thermoplastic composites was mainly between 0.1 and $0.5 \mathrm{~mm} .{ }^{14-16}$ Hashemi ${ }^{17}$ reported that the average residual glass fiber length of SGF/PBT composites was less than $0.3 \mathrm{~mm}$. In this research, the average residual glass fiber length of LGF/PBT composites was longer than the average residual glass fiber length of SGF/ PBT composites.

\subsection{Morphology of LGF/PBT composites}

The SEM observations were performed to investigate the impact fracture surfaces of the LGF/PBT composites with different original glass fiber lengths $(4,8,12,16$ and $20 \mathrm{~mm})$, and the micrographs obtained of the LGF/PBT composites with different original glass fiber length $(4,8,12,16$ and $20 \mathrm{~mm})$ are shown in Fig. 3. These SEM micrographs clearly show some detailed information about glass fiber orientation, glass fiber length and distribution in the matrix resins of the LGF/PBT composites with different original glass fiber length $(4,8,12$, 16 and $20 \mathrm{~mm}$ ). The glass fiber length of the LGF/PBT composites shown in Fig. 3 are longer, and are even longer as the original glass fiber length of the LGF/PBT composites increases. From (Fig. 3a-c), glass fibers of LGF/PBT composites $(4,8$ and $12 \mathrm{~mm})$ are homogeneously dispersed and there is no sign of the phenomenon of reunion in the matrix resins. This indicates that the outstanding mechanical properties of LGF/ PBT composites (4, 8 and $12 \mathrm{~mm}$ ) were obtained. However, from Fig. $3 \mathrm{~d}$ and e, glass fibers of LGF/PBT composites (16 and 

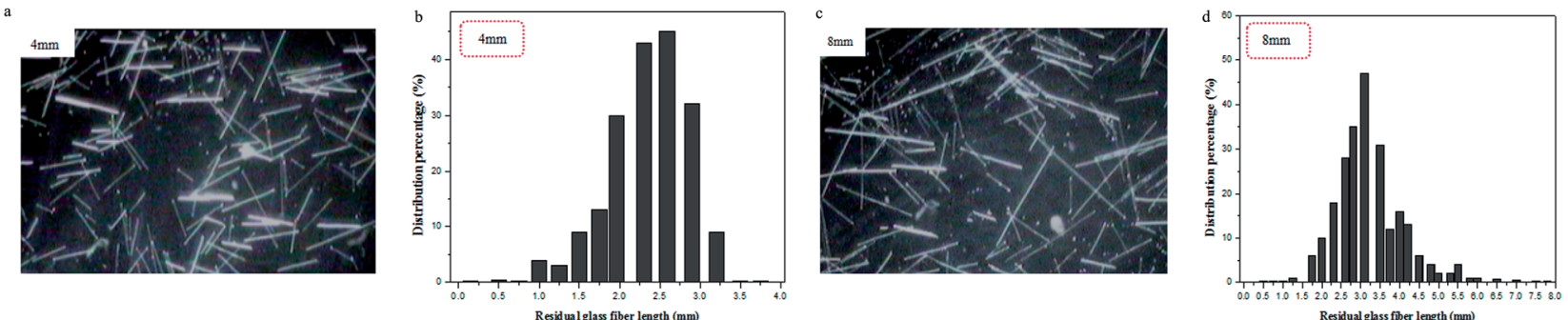

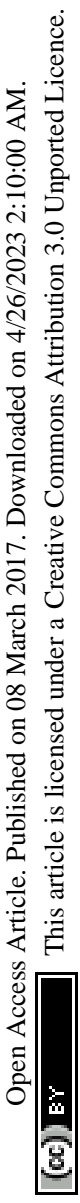
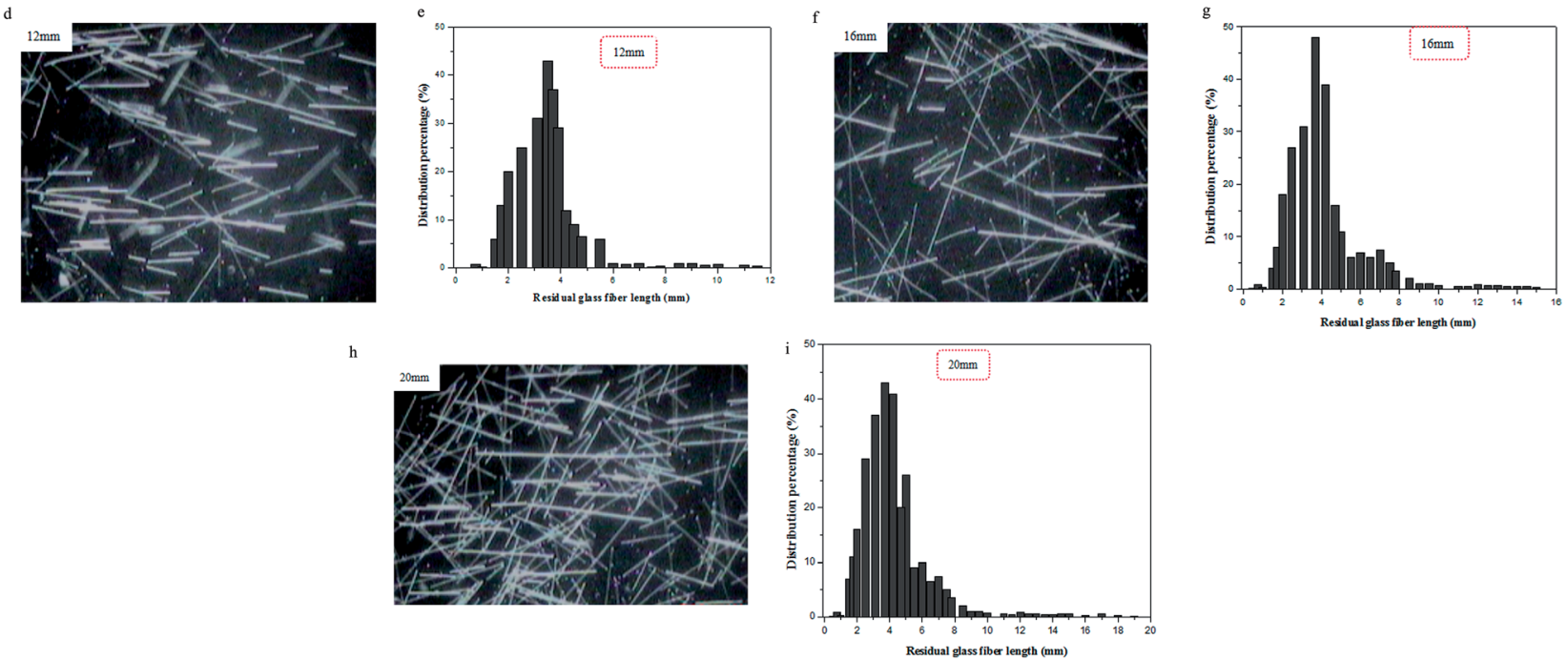

Fig. 2 The residual glass fiber length distribution charts and optical micrographs of residual glass fibers for the LGF (40\%)/PBT composites with different original glass fiber lengths.
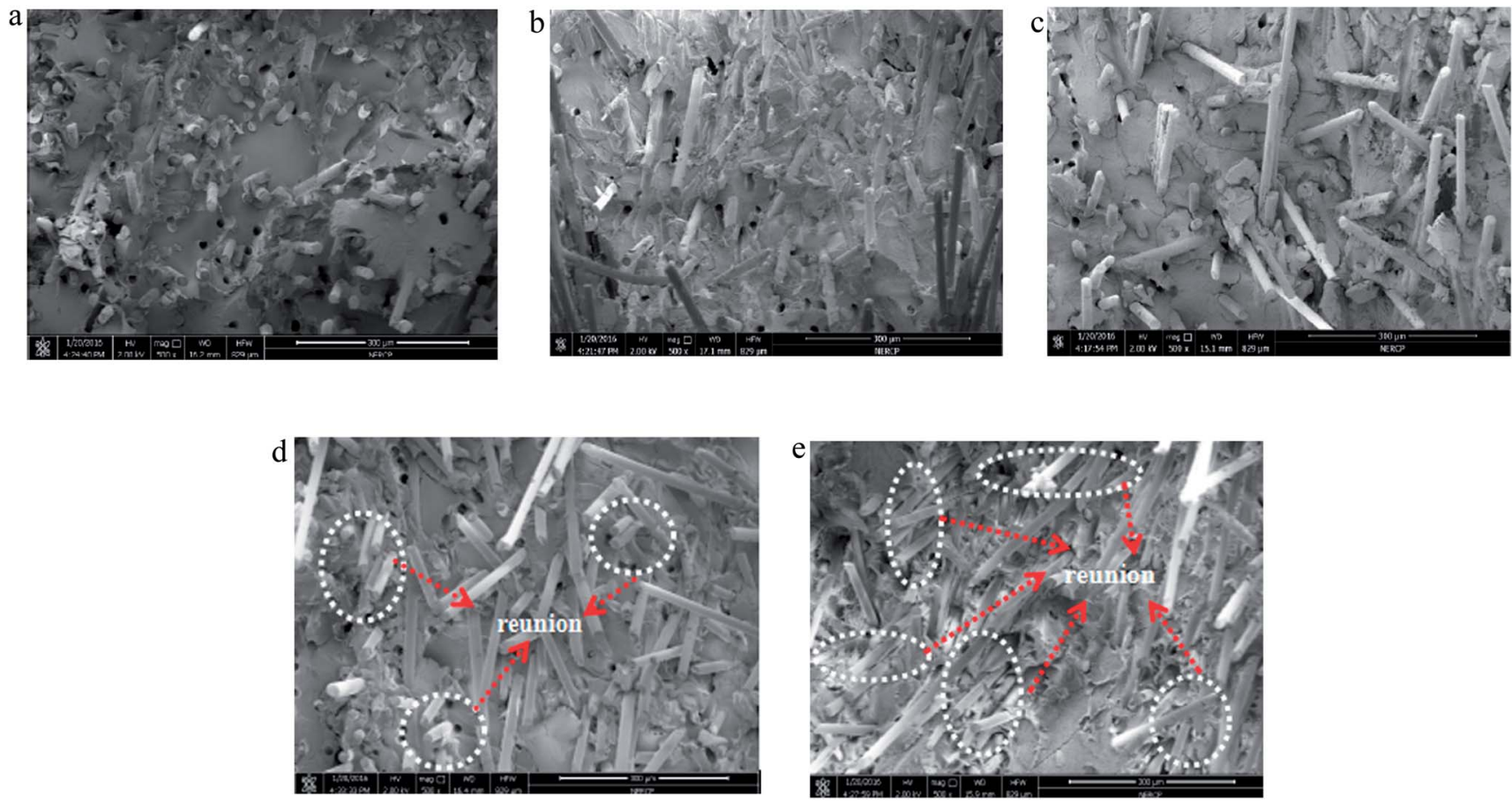

Fig. 3 SEM micrographs of the impact fracture surfaces for the LGF (40\%)/PBT composites with different original glass fiber lengths (a: 4 mm, b: $8 \mathrm{~mm}, \mathrm{c}: 12 \mathrm{~mm}, \mathrm{~d}: 16 \mathrm{~mm}$, e: $20 \mathrm{~mm}$ ) 

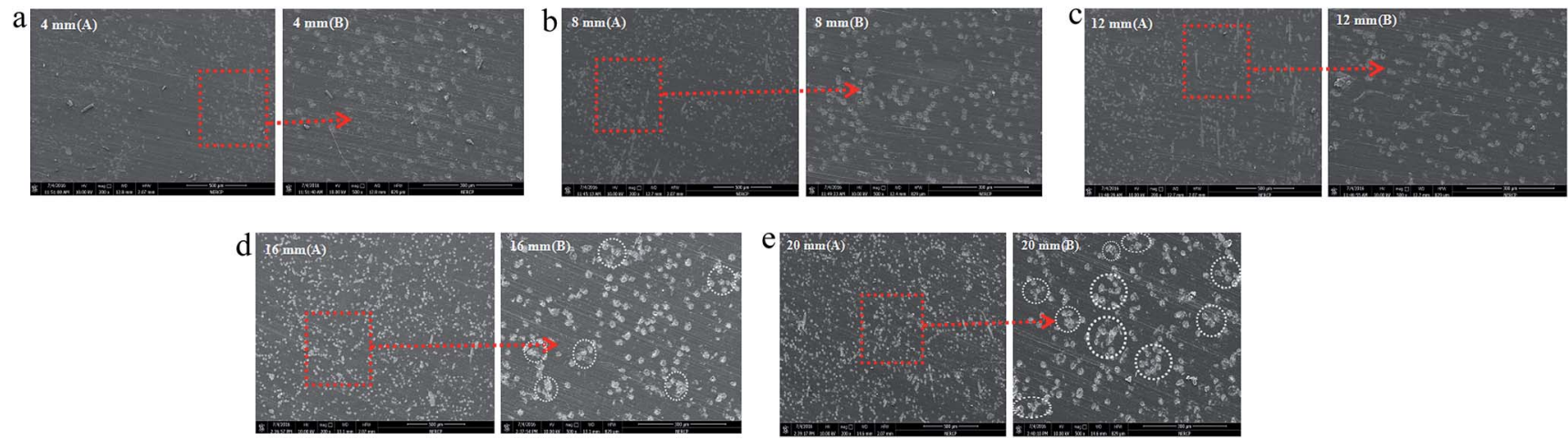

Fig. 4 Glass fiber dispersion state for the LGF (40\%)/PBT composites with different original glass fiber length (4 mm, $8 \mathrm{~mm}, 12 \mathrm{~mm}, 16 \mathrm{~mm}, 20$ $\mathrm{mm})(\mathrm{A}: 100 \times, \mathrm{B}: 500 \times)$.

$20 \mathrm{~mm}$ ) are unevenly dispersed and the phenomenon of reunion does occur in the matrix resins. This leads to the bad mechanical properties that were found in these LGF/PBT composites (16 and $20 \mathrm{~mm}$ ).

\subsection{Glass fiber dispersion state of LGF/PBT composites}

The glass fiber dispersion state of the LGF (40\%)/PBT composites with different original glass fiber length $(4,8,12,16$, and 20 $\mathrm{mm}$ ) have an important effect on the mechanical properties of LGF/PBT composites. Samples of LGF/PBT composites with a notch cut in them were placed in liquid $\mathrm{N}_{2}$, for $2 \mathrm{~h}$, and then rupture surface of the brittle fracture which had occurred was polished with grinding. The fracture surface morphology was analysed using SEM. The glass fiber dispersion state for the LGF $(40 \%) / \mathrm{PBT}$ composites with different original glass fiber lengths $(4,8,12,16$, and $20 \mathrm{~mm})$ are shown in Fig. 4 . As can be seen in Fig. 4, when the original glass fiber length is 4,8 and $12 \mathrm{~mm}$, the glass fibers are homogeneously dispersed and there is no phenomenon of reunion in the PBT matrix resins of the LGF/ PBT composites. This predicts that the composites $(4,8$ and $12 \mathrm{~mm}$ ) will have excellent mechanical properties. But, the glass fibers of the composites show the phenomenon of reunion in the matrix resins of LGF/PBT composites, when the original glass fiber length is 16 and $20 \mathrm{~mm}$. The reason for this is that the residual glass fiber lengths for LGF/PBT composites (16 and $20 \mathrm{~mm}$ ) are too long, and the overlong glass fibers have poor dispersion in the matrix. Because of the bad glass fiber dispersion, LGF/PBT composites (16 and $20 \mathrm{~mm}$ ) do not have good mechanical properties.

\subsection{Linear viscoelastic properties of the LGF/PBT composites}

The rheological properties of the pristine matrix and LGF/PBT composites were investigated in the region of linear viscoelasticity. The linear viscoelastic properties of the pristine matrix and LGF/PBT composites are very sensitive to the structural change of the composites. It will be demonstrated later in this Section using different rheological plots that the pristine matrix and the LGF/PBT composites can bring about new topological structures with a longer relaxation time.
3.4.1 Complex viscosity of the LGF/PBT composites. Complex viscosity versus angle frequency for the pristine matrix and LGF/PBT composites at $240{ }^{\circ} \mathrm{C}$ are shown in Fig. 5. As can be seen in Fig. 5 , the pristine matrix and LGF/PBT composites showed Newtonian behavior in the frequency dependence $Z^{*}(0)$ within the investigated range of shear rates. Furthermore, the complex viscosity of the pristine matrix at the test frequency is the lowest, compared with the composites filled with glass fibers. The complex viscosity of LGF/PBT composites at the test frequency gradually increased as the original glass fiber length of the LGF/PBT composites increased. The reason is that the length of the residual glass fiber of the LGF/PBT composites increases with the increase of the original glass fiber length of the LGF/PBT composites. This is attributed to the LGF hindering the matrix skeleton and the chain segment movement. When the length of the residual glass fiber is longer, the capacity for hindering the molecules' movement is stronger. The complex viscosity of LGF/PBT composites, therefore, increases with increase of the length of the original glass fiber.

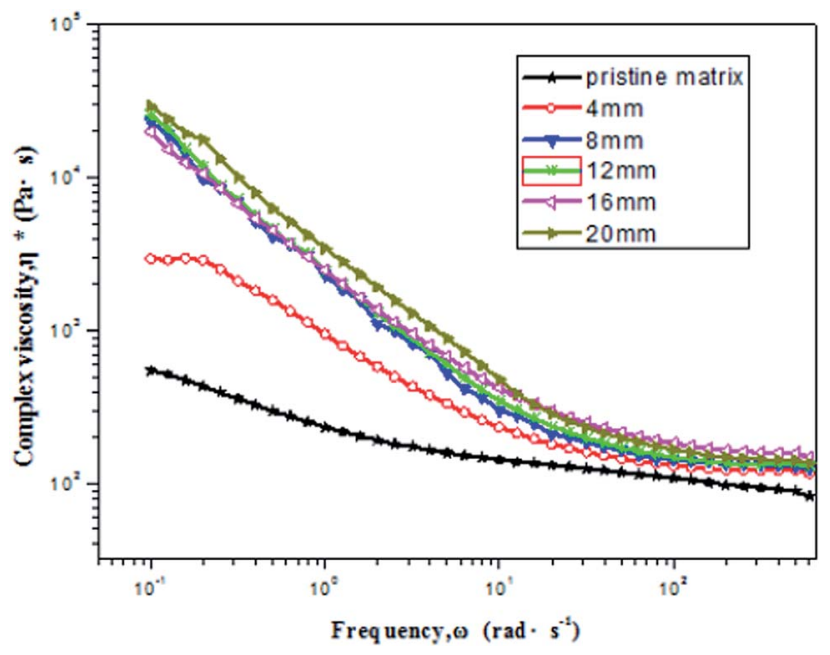

Fig. 5 Complex viscosity versus angle frequency for the pristine matrix and LGF $(40 \%) / P B T$ composites with different lengths of original glass fibers $(4,8,12,16$, and $20 \mathrm{~mm})$ at $240{ }^{\circ} \mathrm{C}$. 

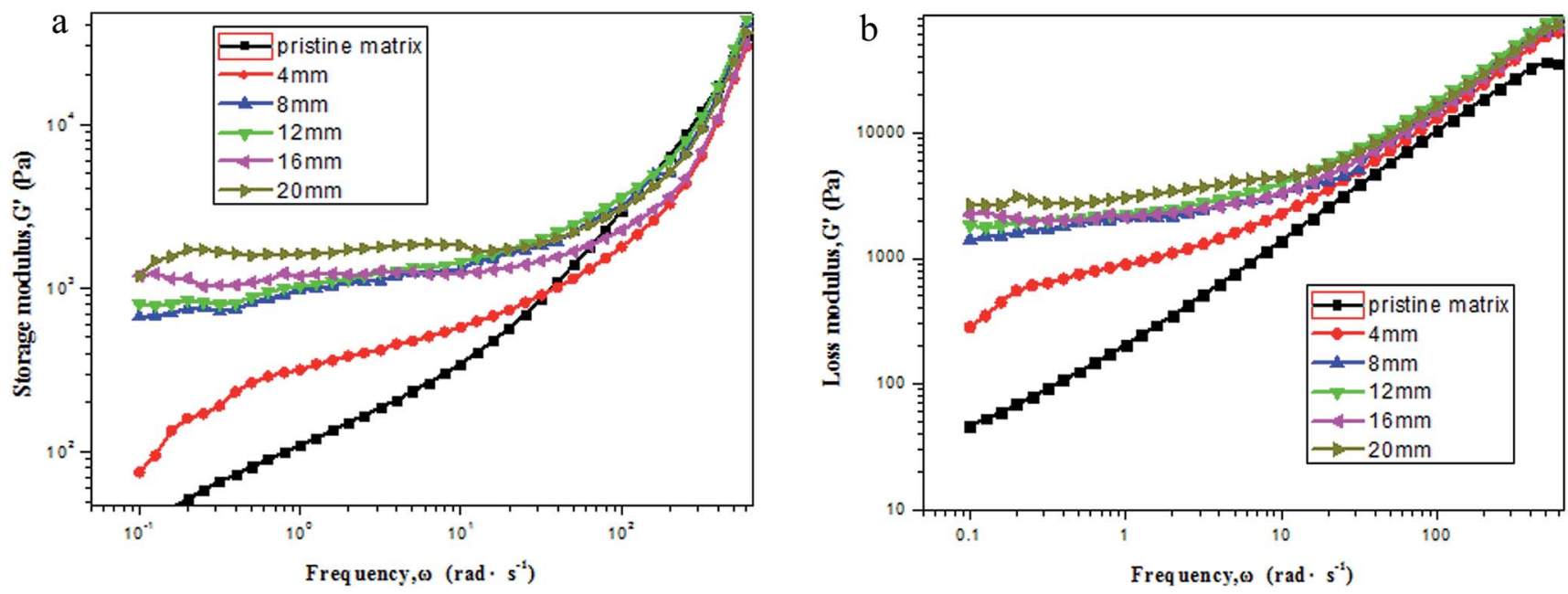

Fig. 6 Storage and loss modulus versus frequency for the pristine matrix and LGF (40\%)/PBT composites with different original glass fiber length $(4,8,12,16,20 \mathrm{~mm})$ at $240{ }^{\circ} \mathrm{C}$.

These are typical characteristics of glass fiber reinforced thermoplastic composites. ${ }^{18}$

3.4.2 Storage and loss modulus of the LGF/PBT composites. Besides zero-shear viscosity, the storage modulus and the loss angle are even more sensitive to the pristine matrix and LGF/PBT composites. The internal structural changes of thermoplastic composites under shear flow can be studied using frequency $(\omega)$ dependences of the storage $\left(G^{\prime}\right)$ and loss $\left(G^{\prime \prime}\right)$ modulus of pristine matrix and LGF/PBT composites. ${ }^{18}$ The $G^{\prime}$ and $G^{\prime \prime}$ of the pristine matrix and LGF/PBT composites plotted as a function of frequency $(\omega)$ is shown in Fig. 6. From Fig. 6, the $G^{\prime}$ and $G^{\prime \prime}$ of the pristine matrix without glass fibers is the lowest. Furthermore, the $G^{\prime}$ and $G^{\prime \prime}$ of the LGF/PBT composites increased with the increase of length of the original glass fibers for LGF/PBT composites at low frequency. This indicated that the addition of LGF to the matrix melt causes an increase of $G^{\prime}$ and $G^{\prime \prime}$ of the LGF/PBT composites (Fig. 6). The length of the residual glass fiber for $\mathrm{LGF} / \mathrm{PBT}$ composites increases gradually with the increase in the length of the original glass fiber of the LGF/PBT composites (see Fig. 2). Furthermore, the increase of length of the residual glass fiber of the LGF/PBT composites hinders the matrix skeleton and chain segment movement for the matrix resins of LGF/PBT composites. $G^{\prime}$ and $G^{\prime \prime}$ of the LGF/ PBT composites, therefore, increase as the length of the original glass fiber increases for LGF/PBT composites.

3.4.3 Loss angle of the LGF/PBT composites. The loss angle $(\tan \delta$ ) versus angle frequency for the pristine matrix and LGF/ PBT composites at $240{ }^{\circ} \mathrm{C}$ are shown in Fig. 7. It has been reported that the loss angle $(\delta)$ of thermoplastic composites is independent of the test frequency $(\omega)$ because polymer composites have a gel-like rheological behavior. ${ }^{19}$ As can be seen from Fig. 7, the tan $\delta$ curves of the pristine matrix and LGF/PBT composites present a definite peak. Furthermore, with the length of original glass fiber increasing, the peak value of tan for the LGF/PBT composites decreases, and the plateau of $\tan \delta$ in LGF/PBT composites becomes longer. ${ }^{\mathbf{1 9 2 0}}$ With the increase in length of the original glass fibers for the LGF/PBT composites,

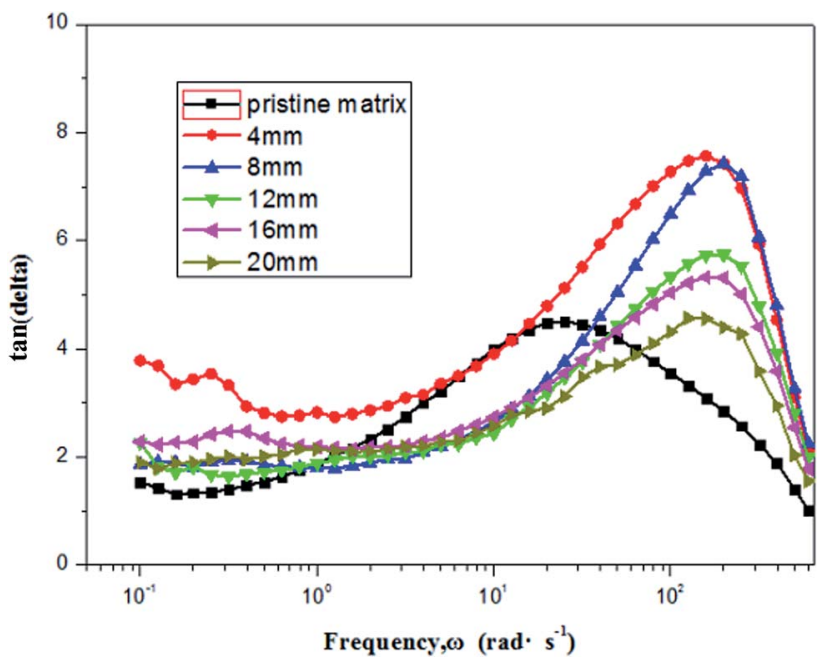

Fig. $7 \tan \delta$ versus angle frequency for the pristine matrix and LGF $(40 \%) / P B T$ composites with different lengths of the original glass fibers $(4,8,12,16$, and $20 \mathrm{~mm})$ at $240{ }^{\circ} \mathrm{C}$.

the $\tan \delta$ of the LGF/PBT composites decreased at low frequency and a plateau appeared in the curve. This is as a result of the LGF hindering the matrix skeleton and increasing the terminal relaxation time. Furthermore, the residual glass fiber length of LGF/PBT composites increases with an increase of the length of the original glass fiber (see Fig. 3). The ability of restricting the chain segment for the matrix resins can be stronger as the length of the original glass fiber increases, and this causes the terminal relaxation time. This observation is in accordance with the experimental results of Zhang et al. ${ }^{21}$ and Graebling. ${ }^{22}$

\subsection{DMA analysis of LGF/PBT composites}

In order to evaluate the dependence of dynamic mechanical properties on temperature, time and scanning frequency, the dynamic measurements of the pristine matrix and LGF/PBT 
composites were carried out using DMA. Dynamic mechanical properties (storage modulus and loss modulus) of pristine matrix and LGF/PBT composites were obtained by dynamic mechanical thermal analysis at test temperature range from -120 to $120{ }^{\circ} \mathrm{C}$. Heating rate is $2{ }^{\circ} \mathrm{C} \mathrm{min}^{-1}$.
3.5.1 Storage modulus of LGF/PBT composites. Effects of different frequencies on the storage modulus of the pristine matrix and LGF/PBT composites with different lengths of the original glass fiber $(4,8,12,16$, and $20 \mathrm{~mm})$ are shown in Fig. 8 and Table 1. As shown in Fig. 8 and Table 1, the storage
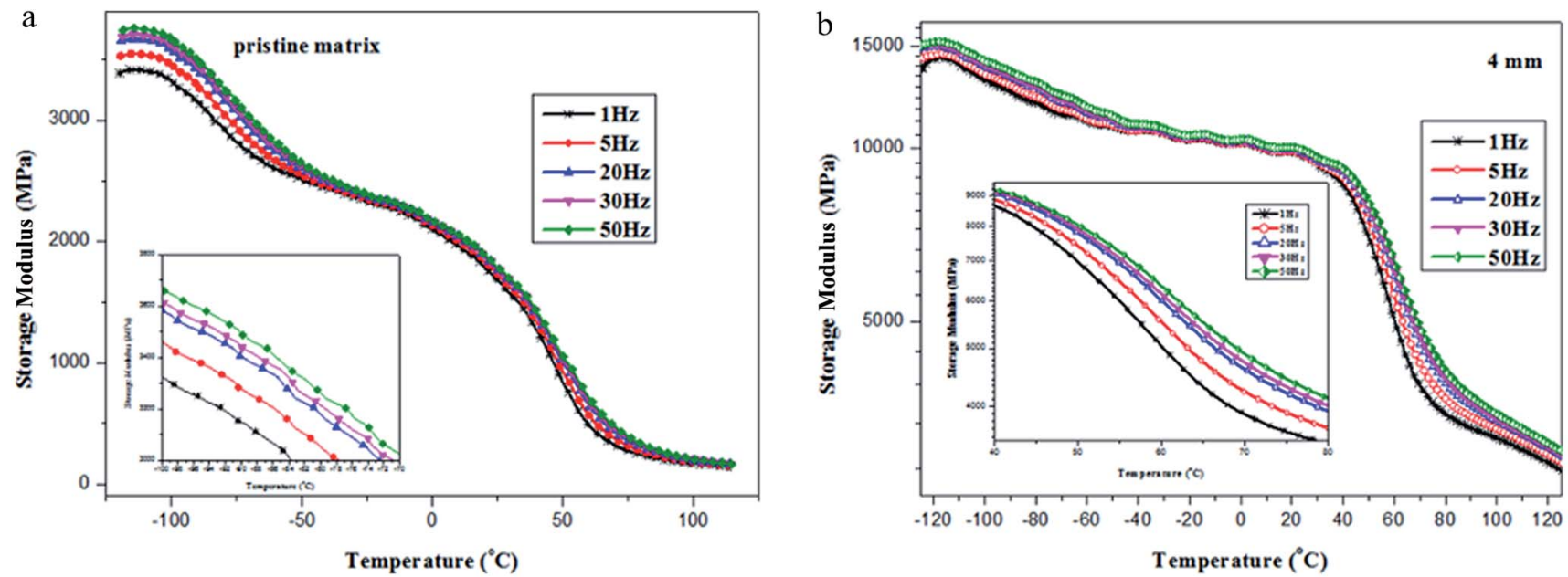

C

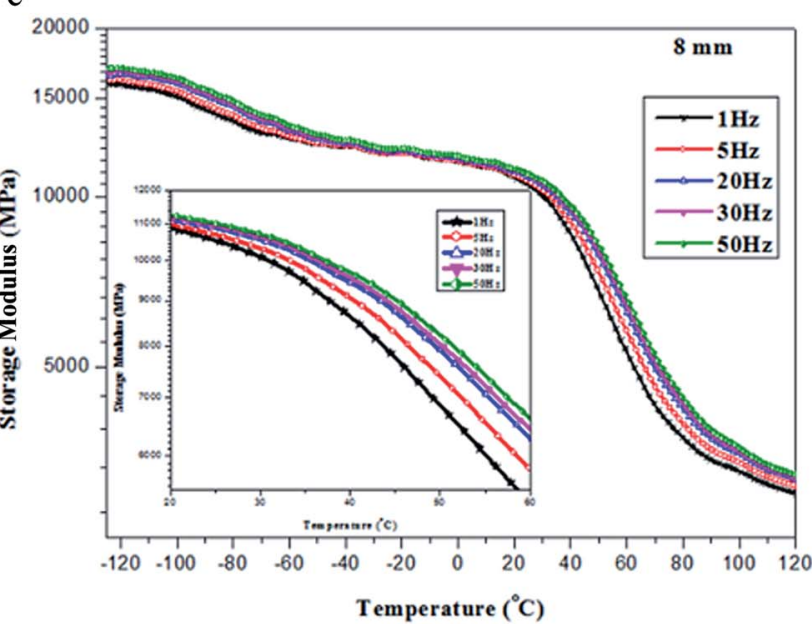

d

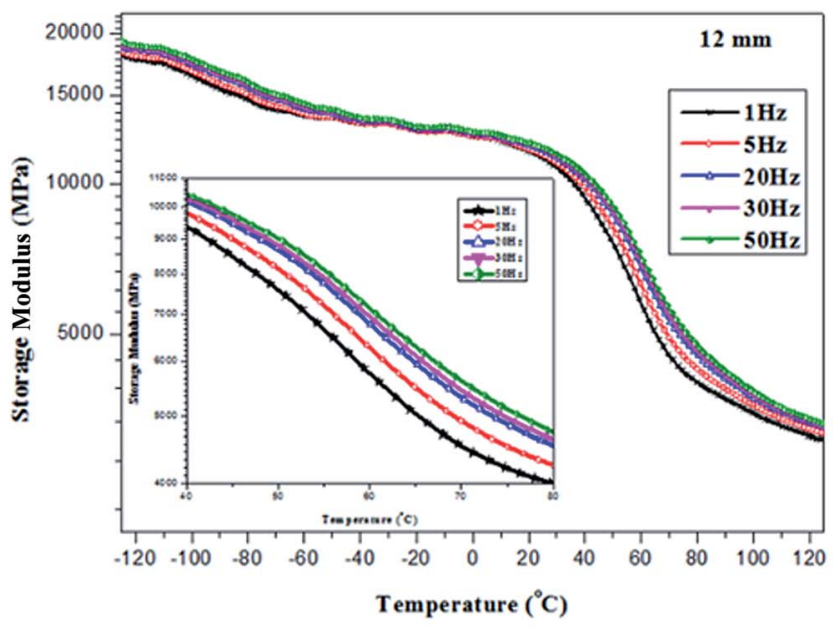

e

f
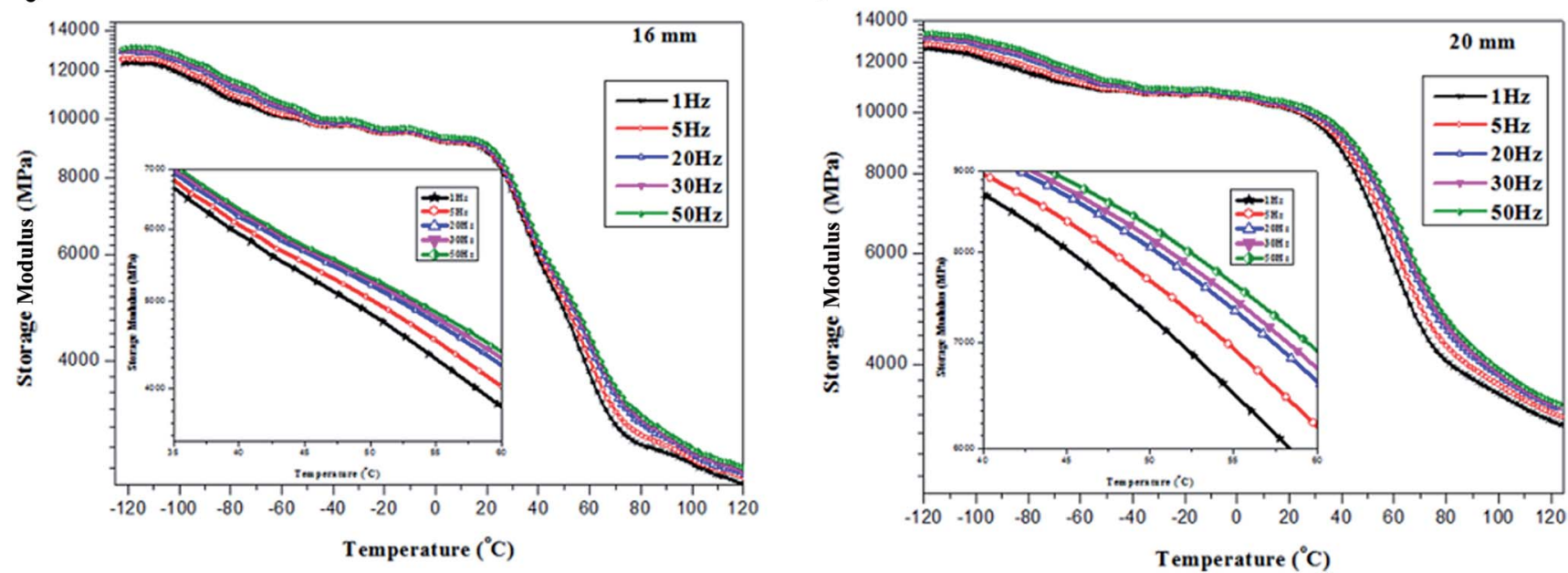

Fig. 8 Effects of different frequencies on the storage modulus of the pristine matrix and LGF (40\%)/PBT composites with different lengths of the original glass fiber $(4,8,12,16$, and $20 \mathrm{~mm})$. Heating rate is $2{ }^{\circ} \mathrm{C} \mathrm{min}$. 
Table 1 The storage modulus of the pristine matrix and LGF (40\%)/PBT composites with different lengths of the original glass fiber (4, 8, 12, 16, and $20 \mathrm{~mm}$ )

\begin{tabular}{|c|c|c|c|c|c|c|}
\hline \multirow[t]{2}{*}{ Pristine matrix } & $E^{\prime}(\mathrm{MPa})-120$ & 3386.23 & 3532.45 & 3657.71 & 3691.28 & 3743.84 \\
\hline & $E^{\prime}(\mathrm{MPa}) 0$ & 2104.35 & 2134.56 & 2154.38 & 2160.31 & 2167.43 \\
\hline & $E^{\prime}(\mathrm{MPa}) 0$ & 10205.31 & 10231.26 & 10286.47 & 10325.34 & 10357.81 \\
\hline \multirow[t]{2}{*}{$8 \mathrm{~mm}$} & $E^{\prime}(\mathrm{MPa})-120$ & 15896.25 & 16204.37 & 16573.63 & 16763.29 & 16994.34 \\
\hline & $E^{\prime}(\mathrm{MPa}) 0$ & 11623.14 & 11611.24 & 11773.32 & 11817.26 & 11854.23 \\
\hline \multirow[t]{2}{*}{$16 \mathrm{~mm}$} & $E^{\prime}(\mathrm{MPa})-120$ & 12617.18 & 12837.35 & 13135.59 & 13218.21 & 13330.49 \\
\hline & $E^{\prime}(\mathrm{MPa}) 0$ & 10548.34 & 10581.27 & 10639.05 & 10694.19 & 10725.25 \\
\hline \multirow[t]{2}{*}{$20 \mathrm{~mm}$} & $E^{\prime}(\mathrm{MPa})-120$ & 12373.91 & 12581.39 & 12914.48 & 12974.23 & 13093.04 \\
\hline & $E^{\prime}(\mathrm{MPa}) 0$ & 9237.82 & 9305.41 & 9355.62 & 9379.05 & 9405.26 \\
\hline
\end{tabular}

modulus of the pristine matrix and the LGF/PBT composites increases with the increasing test frequencies. The reason for this is that the viscoelasticity properties of the pristine matrix and the LGF/PBT composites are a function of temperature, time and frequency. Under the constant stress, chains of molecules within the polymer have to be rearranged to decrease the stress. The modulus of the pristine matrix and the LGF/PBT composites decrease as time increases. So the modulus for the pristine matrix and LGF/PBT composites at a frequency of $50 \mathrm{~Hz}$ (short time) is higher than that at frequency of $1 \mathrm{~Hz}$ (long time). A similar increase in storage modulus of the polymer composites because of the increasing test frequencies were also reported by some researchers. ${ }^{21,23,24}$ From Table 1, the storage modulus of LGF/PBT composites firstly increases and then decreases with the length of the original glass fiber increase. With the length of the original glass fiber of LGF/PBT composites increasing, the length of the residual glass fiber of LGF/PBT composites increases (Fig. 2), which improves the rigidity of the LGF/PBT composites. Furthermore, when the length of the original glass fiber of the LGF/PBT composites is 4, 8 and $12 \mathrm{~mm}$, the glass fibers in the matrix resins of the LGF/ PBT composites are dispersed homogeneously and there is no phenomenon of reunion (Fig. 3 and 4). The storage modulus of the LGF/PBT composites, therefore, increases, when the length of the original glass fiber is 4,8 and $12 \mathrm{~mm}$. But, when the length of the original glass fiber of the LGF/PBT composites is 16 and $20 \mathrm{~mm}$, the glass fibers of LGF/PBT composites are unevenly dispersed and the phenomenon of reunion in the matrix resins occurs, which appears to be a problem for the LGF/PBT composites. Thus, the storage modulus of LGF/PBT composites decreases, when the length of the original glass fiber is 16 or $20 \mathrm{~mm}$. There is a difference between the DMA experimental results and the rheological measurements results obtained using ARES. This could be because the test conditions used for the DMA and ARES were different and as a results the samples were in different states. The rheological experimental results obtained using ARES were from experiments performed at the test temperature of $240{ }^{\circ} \mathrm{C}$, and at this temperature the LGF/PBT composites are in the melting state. However, the DMA experimental results for LGF/PBT composites were acquired at test temperature range between $-120^{\circ} \mathrm{C}$ and $120^{\circ} \mathrm{C}$, and the LGF/PBT composites were not melting, but still at the solid phase. The different states of the LGF/PBT composites give an indication of the different properties of the composites. Thus, the storage modulus results for the LGF/PBT composites are inconsistent when determined by DMA and ARES. Over the temperature range between $-120{ }^{\circ} \mathrm{C}$ and $120{ }^{\circ} \mathrm{C}$, the storage modulus curves of the LGF/PBT composites are in a glassy state, with glass-rubber relaxation and a rubbery plateau. Firstly, in the glass state, the temperature range is from -120 to $40{ }^{\circ} \mathrm{C}$, because of the chain conformations freezing into an amorphous rigid network, and thus, the higher storage modulus values of LGF/PBT composites were displayed. Secondly, in the glass-rubber relaxation period, the temperature range is from 40 to $80^{\circ} \mathrm{C}$, and the test temperature is close to the glass transition temperature $\left(T_{\mathrm{g}}\right)$ for LGF/PBT composites, which leads to the movement of small parts of the polymer chains. The storage modulus of LGF/PBT composites arises from a notable drop in $T_{\mathrm{g}}$. Thirdly, in the rubbery plateau, the temperature range is from $80-120^{\circ} \mathrm{C}$. With glass-rubber relaxation, because of longrange motion of the chain segments, the glass for the LGF/PBT composites transforms to a rubber-like state..$^{25,26}$

3.5.2 Loss modulus of LGF/PBT composites. Effects of different frequencies $(1,5,20,30$ and $50 \mathrm{~Hz})$ on loss modulus of the pristine matrix and LGF/PBT composites when heating rate is $2{ }^{\circ} \mathrm{C} \mathrm{min}{ }^{-1}$ are shown in Fig. 9. As shown in Fig. 8 and Table 2, the loss modulus curves of the pristine matrix and LGF/PBT composites show two transitions ( $\alpha$ transition and $\beta$ transition). The temperature range of the $\alpha$ transition for the pristine matrix and the LGF/PBT composites is between 45 and $70{ }^{\circ} \mathrm{C}$, which is related to the $T_{\mathrm{g}}$ of the PBT matrix resins for LGF/PBT composites. However, the temperature range of the $\beta$ transition for the pristine matrix and LGF/PBT composites is between -100 and $-70{ }^{\circ} \mathrm{C}$, which is related to the $T_{\mathrm{g}}$ of the TPU molecules for the pristine matrix and the LGF/PBT composites. As can be seen from Fig. 9 and Table 2, the $T_{\mathrm{g}}$ and the intensity of the loss modulus peaks for the LGF/PBT composites increase with increasing test frequencies. Furthermore, $\alpha$-transition and $\beta$-transition peaks of the pristine matrix and LGF/PBT composites shifted to higher temperatures as the test frequencies increase (see Fig. 9). This is because of the increasing speed of motion of the molecules, and indicates that at higher 

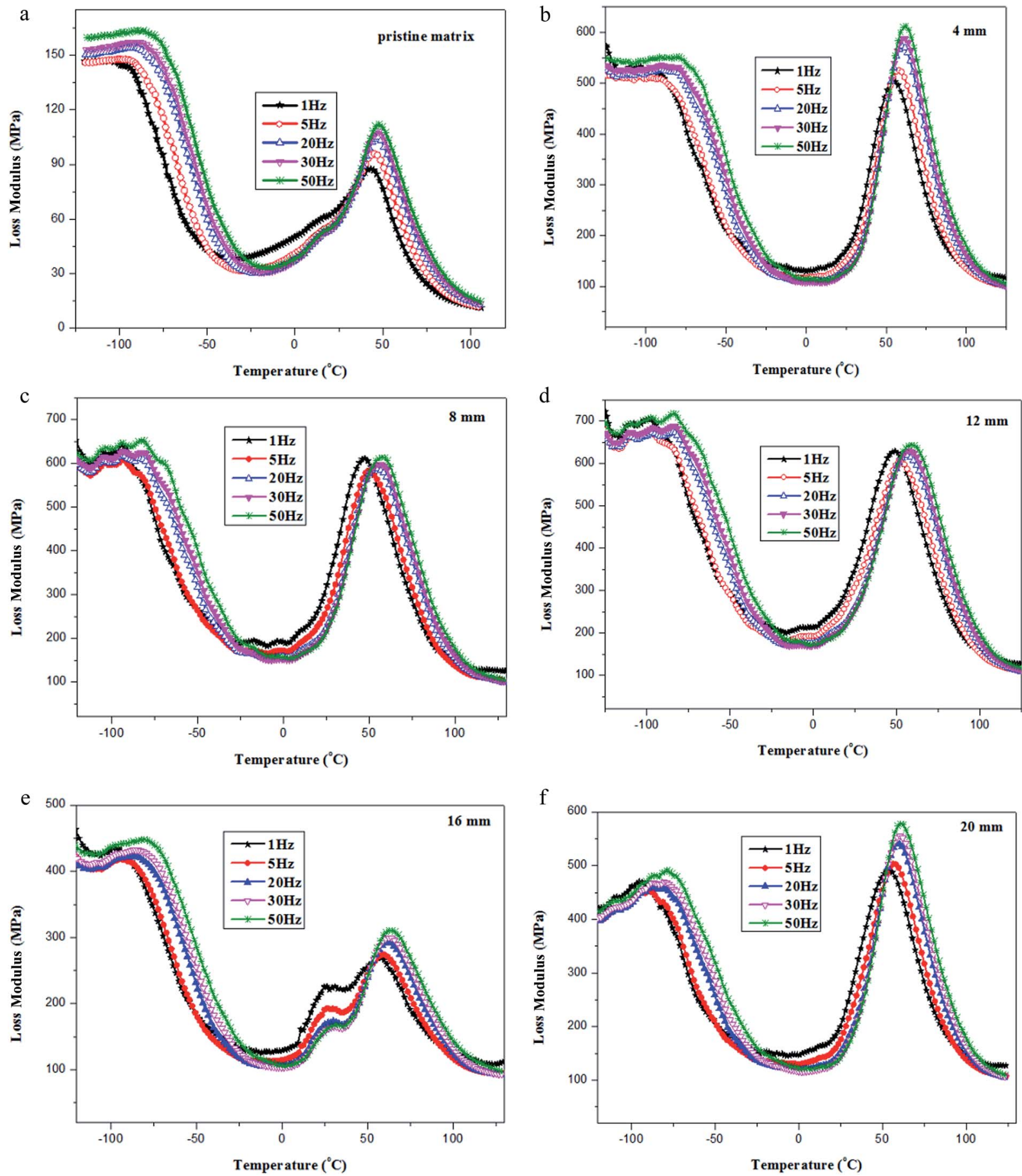

Fig. 9 Effects of different frequencies on the loss modulus of the pristine matrix and LGF $(40 \%) / P B T$ composites with different lengths of original glass fibers $(4,8,12,16$, and 20$)$, when the heating rate is $2^{\circ} \mathrm{C} \mathrm{min}^{-1}$.

frequencies, more movement of the atoms for the composites will be required to match the imposed frequency, which can be attained with higher temperatures. Other researchers have also reported similar experimental results. ${ }^{21,27,28}$ The $T_{\mathrm{g}}$ of $\alpha$-transition and $\beta$-transition for LGF/PBT composites increase with the length of the original glass fiber increase, which occurs because the molecular motion of the matrix resin was restricted in the LGF/PBT composites.
3.5.3 $\tan \delta$ of LGF/PBT composites. It can be seen in Fig. 10 that for the pristine matrix and LGF/PBT composites the $\alpha$ and $\beta$ relaxation peaks appear in the test temperature range. From Fig. 10 and Table 3, the temperature range of the $\alpha$ relaxation for the pristine matrix and LGF/PBT composites is between $55{ }^{\circ} \mathrm{C}$ and $70{ }^{\circ} \mathrm{C}$, which corresponds to the $T_{\mathrm{g}}$ of the PBT matrix. The temperature range of the $\beta$ relaxation for the pristine matrix and LGF/PBT composites is between $-90{ }^{\circ} \mathrm{C}$ and $-65^{\circ} \mathrm{C}$, which 
Table 2 The glass transition temperatures $\left(T_{\mathrm{g}}\right)$ of the pristine matrix and LGF (40\%)/PBT composites with different lengths of the original glass fiber $(4,8,12,16,20)$ at different frequencies on loss modulus

\begin{tabular}{|c|c|c|c|c|c|c|}
\hline \multirow[t]{2}{*}{ Pristine matrix } & $T_{\mathrm{g}}\left({ }^{\circ} \mathrm{C}\right) \alpha$ & 48.13 & 51.05 & 54.31 & 55.07 & 56.16 \\
\hline & $T_{\mathrm{g}}\left({ }^{\circ} \mathrm{C}\right) \beta$ & -92.02 & -89.47 & -82.95 & -80.96 & -79.25 \\
\hline $4 \mathrm{~mm}$ & $T_{\mathrm{g}}\left({ }^{\circ} \mathrm{C}\right) \beta$ & -91.17 & -88.05 & -80.83 & -79.84 & -78.73 \\
\hline \multirow[t]{2}{*}{$8 \mathrm{~mm}$} & $T_{\mathrm{g}}\left({ }^{\circ} \mathrm{C}\right) \alpha$ & 50.34 & 52.89 & 56.86 & 58.28 & 59.98 \\
\hline & $T_{\mathrm{g}}\left({ }^{\circ} \mathrm{C}\right) \beta$ & -90.32 & -87.20 & -79.46 & -79.19 & -78.06 \\
\hline \multirow[t]{2}{*}{$16 \mathrm{~mm}$} & $T_{\mathrm{g}}\left({ }^{\circ} \mathrm{C}\right) \alpha$ & 57.71 & 59.69 & 63.01 & 63.67 & 64.82 \\
\hline & $T_{\mathrm{g}}\left({ }^{\circ} \mathrm{C}\right) \beta$ & -89.67 & -85.47 & -79.08 & -78.35 & -76.89 \\
\hline \multirow[t]{2}{*}{$20 \mathrm{~mm}$} & $T_{\mathrm{g}}\left({ }^{\circ} \mathrm{C}\right) \alpha$ & 57.03 & 60.13 & 62.26 & 63.68 & 65.46 \\
\hline & $T_{\mathrm{g}}\left({ }^{\circ} \mathrm{C}\right) \beta$ & -89.32 & -80.46 & -78.41 & -77.84 & -75.58 \\
\hline
\end{tabular}

is related to the $T_{\mathrm{g}}$ of the TPU for the pristine matrix and the LGF/PBT composites. Furthermore, the $T_{\mathrm{g}}$ of the pristine matrix and the LGF/PBT composites increases with the length of the original glass fibers and as the test frequencies increase. When the test frequencies of the pristine matrix and LGF/PBT composites increase, the motion speed of the molecules was improved. The $T_{\mathrm{g}}$ of the pristine matrix and the LGF/PBT composites, therefore, shifted to higher temperature. ${ }^{26}$ However, when the length of the original glass fiber is longer, the length of the residual glass fiber increases (see Fig. 2). The ability of chain movement for the LGF/PBT composites was restricted. Thus, the $T_{\mathrm{g}}$ for the LGF/PBT composites increases with the increase in the length of the original glass fiber.

3.5.4 Calculation of the activation energy. The apparent activation energy for $\left(T_{\mathrm{g}}\right), \Delta E_{\mathrm{a}}$, can be used to characterize the relationship between the shift of $T_{\mathrm{g}}$ and frequency. It is noted that whereas $T_{\mathrm{g}}$ represents the relationship between the mobility of polymer chains and temperature, $\Delta E_{\mathrm{a}}$ represents a relationship between mobility and time scale and could be considered as representing the energy barrier of $T_{\mathrm{g}}$ relaxation. In order to determine the effect of frequencies on the dynamic mechanical properties of the pristine matrix and LGF/PBT composites, DMA tests of the pristine matrix and LGF/PBT composites were performed over a temperature range of $-125^{\circ} \mathrm{C}$ to $125^{\circ} \mathrm{C}$ and at five different frequencies $(1,5,20,30$ and $50 \mathrm{~Hz})$. The temperature dependence of $\tan \delta$ for the pristine matrix and LGF/PBT composites represents the five frequencies studied. From Fig. 9 and 10, Tables 2 and 3, it can be deduced that the effect of the frequencies on peak magnitude shows a clear tendency, when frequencies range from 1 to $50 \mathrm{~Hz}$. It has been suggested that it is possible to interrelate the temperature at which a relaxation process is observed with the frequency of excitation $(f)$ by using the Arrhenius equation (especially over a limited frequency range), which predicts the change in relaxation time as the $T_{\mathrm{g}}$ is approached from temperatures above the $T_{\mathrm{g}}$ because of the decrease of free volume. ${ }^{29}$

According to the classic Arrhenius equation, molecular relaxation time(s) may be expressed as follows:

$$
\tau=\tau_{0} \mathrm{e}^{\frac{\Delta E-\gamma \sigma}{R T}}
$$

where $\Delta E$ and $\sigma$ are the activation energy of the relaxation process and the stress, respectively, $\gamma$ is the variable, $R$ is the gas constant, $T$ is the absolute temperature and $t_{0}$ is a hypothetical relaxation time at an infinite temperature.

Here, the stress $(\sigma)$ is small, so the following simplified version is used:

$$
\begin{gathered}
\tau=\tau_{0} \mathrm{e}^{\frac{\Delta E}{R T}} \\
\ln \tau=\ln \tau_{0}+\frac{\Delta E}{R T}
\end{gathered}
$$

The relaxation times were obtained from the relationship:

$$
\tau=\frac{1}{\omega}
$$

A combination of eqn (5) and (6) leads to:

$$
\begin{aligned}
\ln \left(\frac{1}{\omega}\right) & =\ln \tau_{0}+\frac{\Delta E}{R T} \\
\omega & =2 \pi f \\
\ln (2 \pi f) & =-\ln \tau_{0}-\frac{\Delta E}{R T}
\end{aligned}
$$

The Arrhenius equation has the following form:

$$
f=f_{0} \exp \left(\frac{-\Delta E}{R T}\right)
$$

where $f$ and $f_{0}$ are the test frequencies and a constant, respectively. Fig. 11 shows the linear relationship between $\ln f_{\max }$ against the reciprocal of $1 / T$.

According to the equation, a plot of $\ln$ fversus $1 / T$ should give a straight line with a slope that is proportional to the apparent activation energy (energy barrier to motion) associated to the $\alpha$ and $\beta$-relaxation processes of the pristine matrix and LGF/PBT composites. The calculated activation energies of loss modulus and $\tan \delta$ of the pristine matrix and LGF/PBT composites according to eqn (10) are shown in Table 4 . As can be seen from 
a

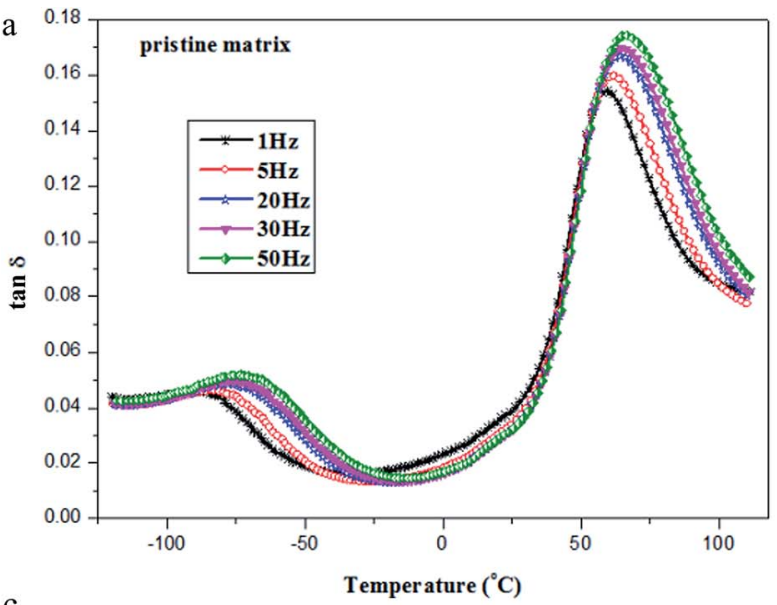

$\mathrm{C}$

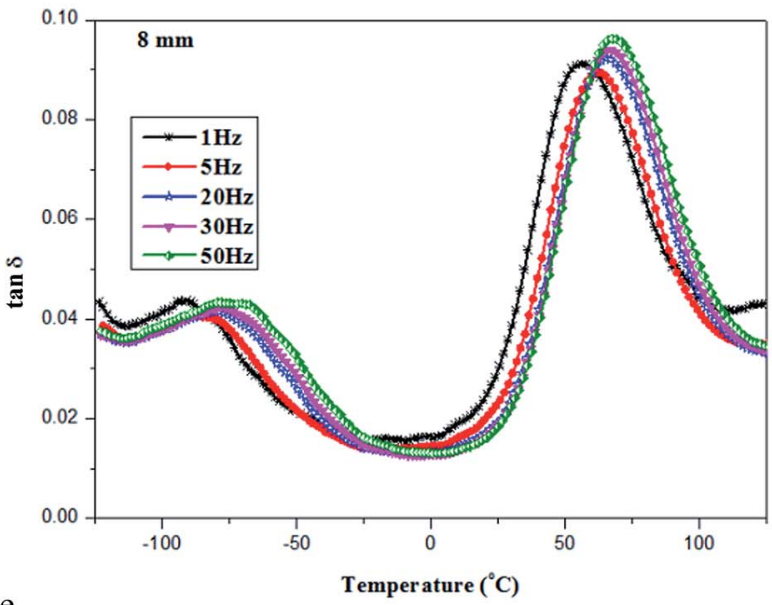

e

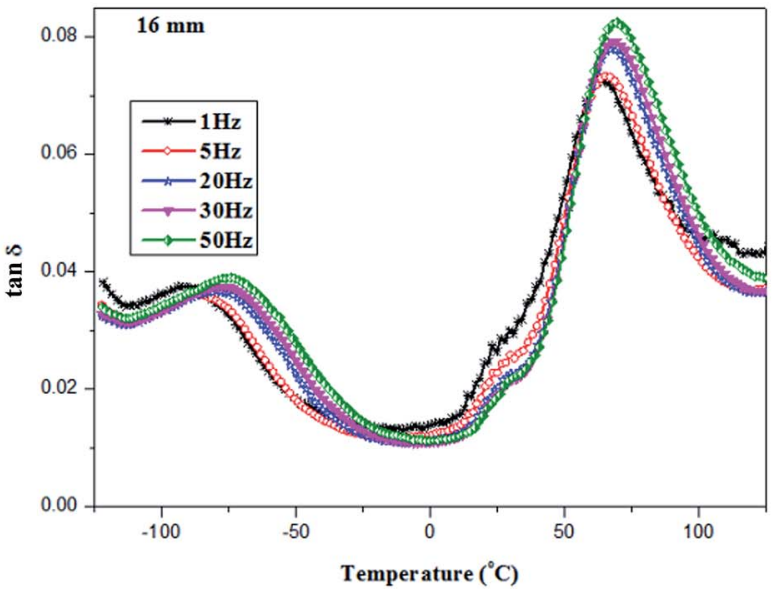

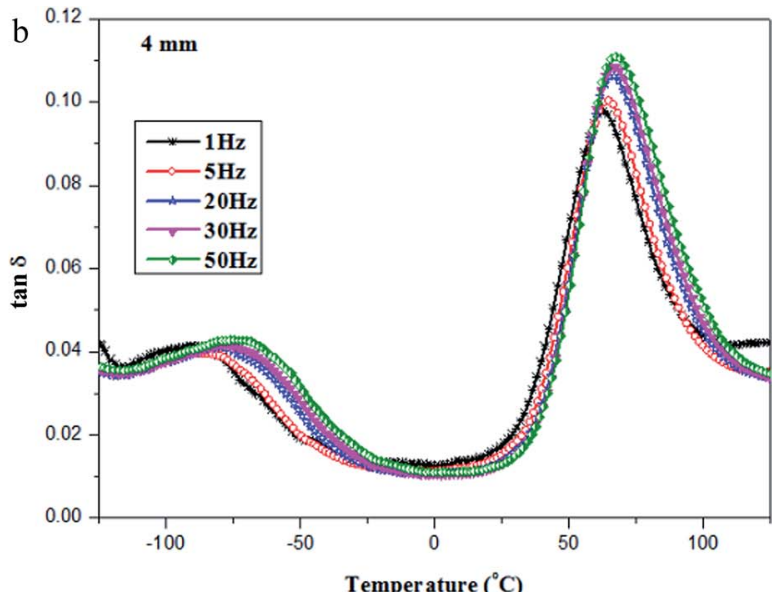

d

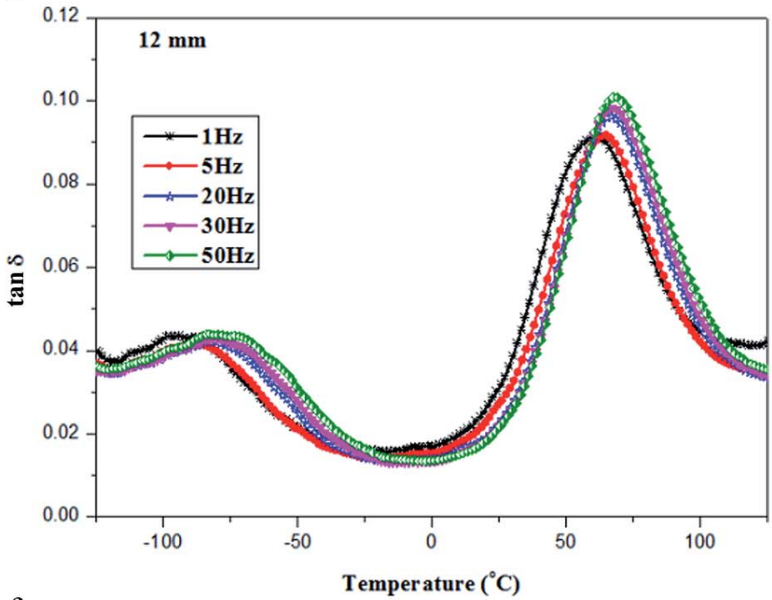

f

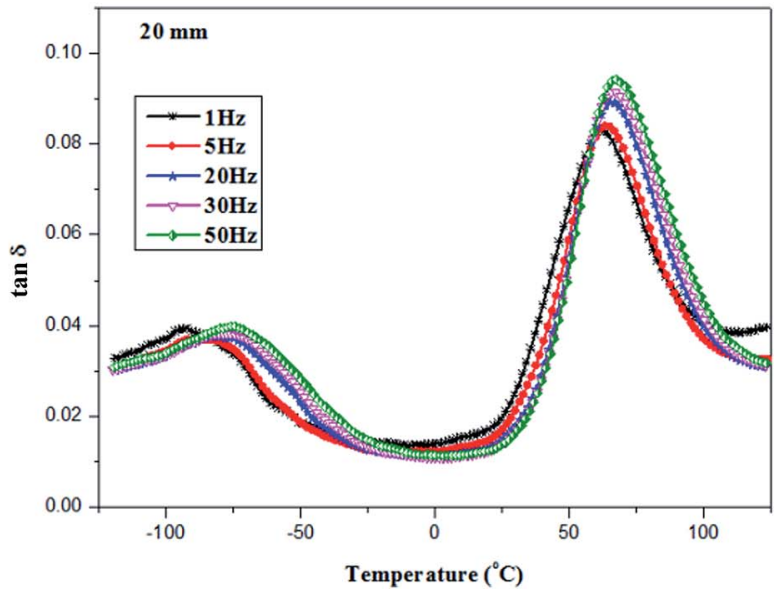

Fig. 10 Effects of different frequencies on $\tan \delta$ of the pristine matrix and LGF (40\%)/PBT composites with different lengths of the original glass fibers $(4,8,12,16$, and 20$)$, with a heating rate of $2{ }^{\circ} \mathrm{C} \mathrm{min}^{-1}$.

Table 4, the activation energies of the $\alpha$ - and $\beta$-relaxation processes of the loss modulus and $\tan \delta$ of the pristine matrix are higher than that of the LGF/PBT composites. This is because the glass fibers used for LGF/PBT composites hinder the movement of the chain segment. Furthermore, from Fig. 11, it can be seen that the activation energies of the $\alpha$ - and $\beta$-relaxation processes of loss modulus and $\tan \delta$ of LGF/PBT composites gradually increased with the original glass fibers, and this could be explained because of the increasing length of the residual glass fibers, which increases the barrier for the movement of the matrix resin. The activation energies of the $\alpha$-relaxation process of loss modulus and $\tan \delta$ of the pristine matrix and LGF/PBT composites are higher than the activation energies of the $\beta$ relaxation process of loss modulus and $\tan \delta$ of the pristine matrix and LGF/PBT composites. This can be because the TPU has outstanding fluidity which reduces the barrier for the 
Table 3 The glass transition temperatures of the pristine matrix and LGF (40\%)/PBT composites with different lengths of the original glass fiber $(4,8,12,16$, and 20$)$ at different frequencies on $\tan \delta$

\begin{tabular}{|c|c|c|c|c|c|c|}
\hline Frequencies (Hz) & & 1 & 5 & 20 & 30 & 50 \\
\hline \multirow[t]{2}{*}{ Pristine matrix } & $T_{\mathrm{g}}\left({ }^{\circ} \mathrm{C}\right) \alpha$ & 56.03 & 58.21 & 61.78 & 63.52 & 64.02 \\
\hline & $T_{\mathrm{g}}\left({ }^{\circ} \mathrm{C}\right) \beta$ & -89.13 & -88.01 & -82.71 & -80.12 & -75.41 \\
\hline \multirow[t]{2}{*}{$4 \mathrm{~mm}$} & $T_{\mathrm{g}}\left({ }^{\circ} \mathrm{C}\right) \alpha$ & 57.43 & 60.55 & 64.23 & 65.37 & 65.93 \\
\hline & $T_{\mathrm{g}}\left({ }^{\circ} \mathrm{C}\right) \beta$ & -88.62 & -87.21 & -79.89 & -77.96 & -73.31 \\
\hline \multirow[t]{2}{*}{$8 \mathrm{~mm}$} & $T_{\mathrm{g}}\left({ }^{\circ} \mathrm{C}\right) \alpha$ & 61.25 & 63.95 & 65.07 & 66.64 & 67.05 \\
\hline & $T_{\mathrm{g}}\left({ }^{\circ} \mathrm{C}\right) \beta$ & -86.64 & -85.52 & -79.83 & -77.84 & -72.46 \\
\hline \multirow[t]{2}{*}{$12 \mathrm{~mm}$} & $T_{\mathrm{g}}\left({ }^{\circ} \mathrm{C}\right) \alpha$ & 62.61 & 64.13 & 65.93 & 67.05 & 67.92 \\
\hline & $T_{\mathrm{g}}\left({ }^{\circ} \mathrm{C}\right) \beta$ & -86.92 & -76.14 & -72.46 & -71.32 & -69.34 \\
\hline \multirow[t]{2}{*}{$16 \mathrm{~mm}$} & $T_{\mathrm{g}}\left({ }^{\circ} \mathrm{C}\right) \alpha$ & 62.95 & 65.37 & 67.12 & 68.09 & 68.35 \\
\hline & $T_{\mathrm{g}}\left({ }^{\circ} \mathrm{C}\right) \beta$ & -85.12 & -75.41 & -71.48 & -70.59 & -67.17 \\
\hline $20 \mathrm{~mm}$ & $T_{\mathrm{g}}\left({ }^{\circ} \mathrm{C}\right) \alpha$ & 63.38 & 65.41 & 67.35 & 68.23 & 68.69 \\
\hline
\end{tabular}
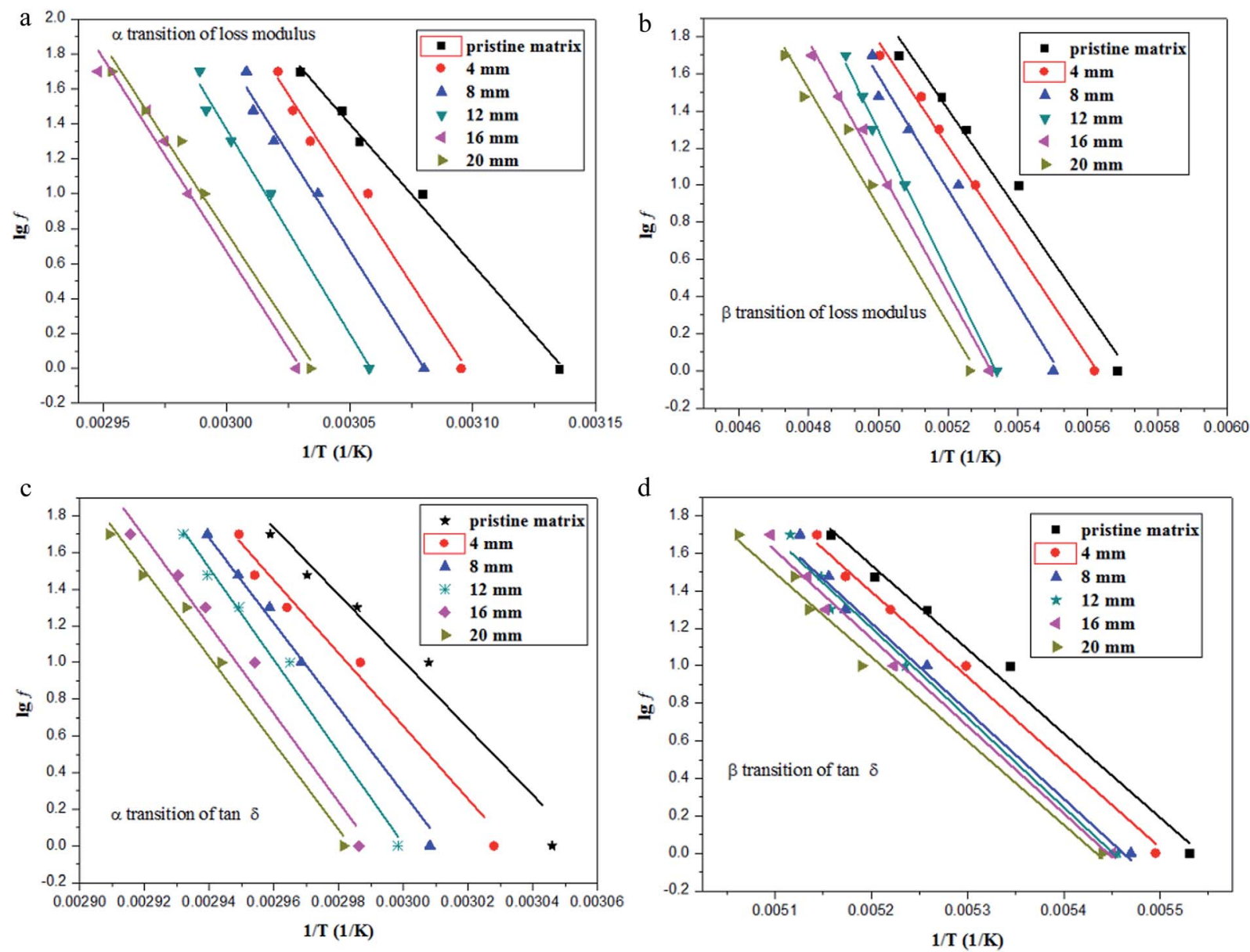

Fig. 11 Arrhenius plots of relaxation times versus $1 / T$ and the respective linear fits of the pristine matrix and LGF/PBT composites with different original glass fiber lengths $(4,8,12,16$, and $20 \mathrm{~mm})$.

movement of matrix resin. Zhang et al. ${ }^{21}$ and Li et al. ${ }^{30}$ reported that the activation energies for the $T_{\mathrm{g}}$ relaxation determined from the loss tangent $(\tan \delta)$ peaks are more reliable than using the loss modulus $\left(E^{\prime \prime}\right)$ criterion.

\subsection{DSC analysis of LGF/PBT composites}

The crystallization and melting behavior of the pristine matrix and LGF/PBT composites with different lengths of original glass fibers $(4,8,12,16$ and $20 \mathrm{~mm})$ were studied using DSC. DSC thermograms of the pristine matrix and LGF/PBT composites with different lengths of original glass fibers $(4,8,12,16$ and 20 $\mathrm{mm}$ ) are shown in Fig. 12 and 13, respectively. Table 5 shows the crystallization temperature $\left(T_{\mathrm{c}}\right)$ and percent crystallinity $\left(X_{\mathrm{c}}\right)$ of the pristine matrix and LGF/PBT composites. From the crystallization curves shown in Fig. 12, the $T_{\mathrm{c}}$ of the pristine matrix is the highest, when compared with the $T_{\mathrm{c}}$ of LGF/PBT 
Table 4 The glass transition temperature $\left(T_{\mathrm{g}}\right)$ of the pristine matrix and LGF/PBT composites at different frequencies

\begin{tabular}{|c|c|c|c|c|}
\hline \multirow[b]{2}{*}{ Samples } & \multicolumn{2}{|c|}{$\begin{array}{l}\Delta E_{\mathrm{a}}\left(\mathrm{kJ} \mathrm{mol}^{-1}\right) \\
\text { of loss modulus }\end{array}$} & \multicolumn{2}{|c|}{$\begin{array}{l}\Delta E_{\mathrm{a}}\left(\mathrm{kJ} \mathrm{mol}^{-1}\right) \\
\text { of } \tan \delta\end{array}$} \\
\hline & $\alpha$ & $\beta$ & $\alpha$ & $\beta$ \\
\hline Pristine matrix & 133.96 & 22.64 & 151.33 & 33.59 \\
\hline $4 \mathrm{~mm}$ & 172.07 & 23.53 & 181.83 & 37.82 \\
\hline $8 \mathrm{~mm}$ & 184.93 & 25.52 & 192.56 & 39.02 \\
\hline $12 \mathrm{~mm}$ & 194.62 & 31.96 & 208.71 & 39.83 \\
\hline $16 \mathrm{~mm}$ & 183.47 & 28.16 & 200.14 & 38.86 \\
\hline $20 \mathrm{~mm}$ & 178.36 & 26.32 & 195.42 & 37.26 \\
\hline
\end{tabular}

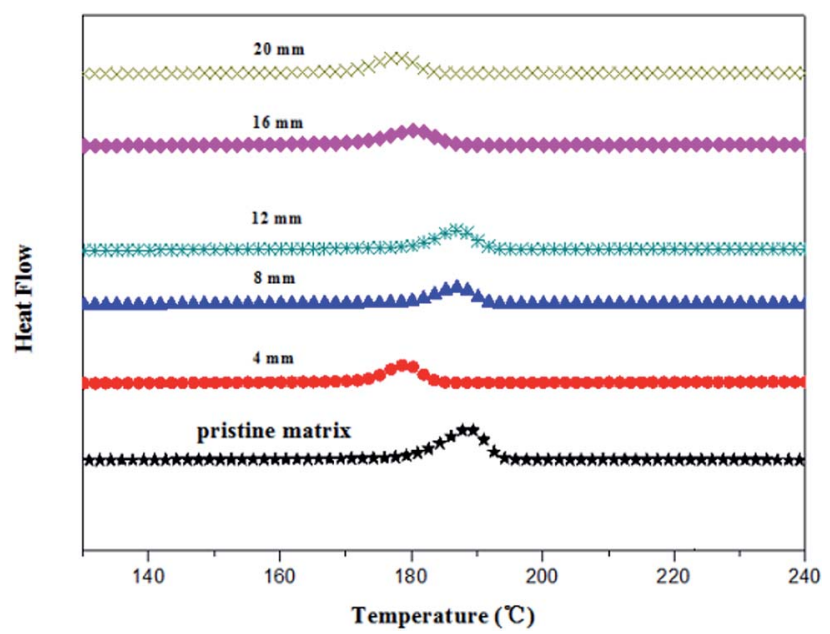

Fig. 12 DSC crystallization curves of the pristine matrix and LGF (40\%)/ PBT composites with different lengths of the original glass fibers $(4,8$, 12,16 , and $20 \mathrm{~mm}$ ).

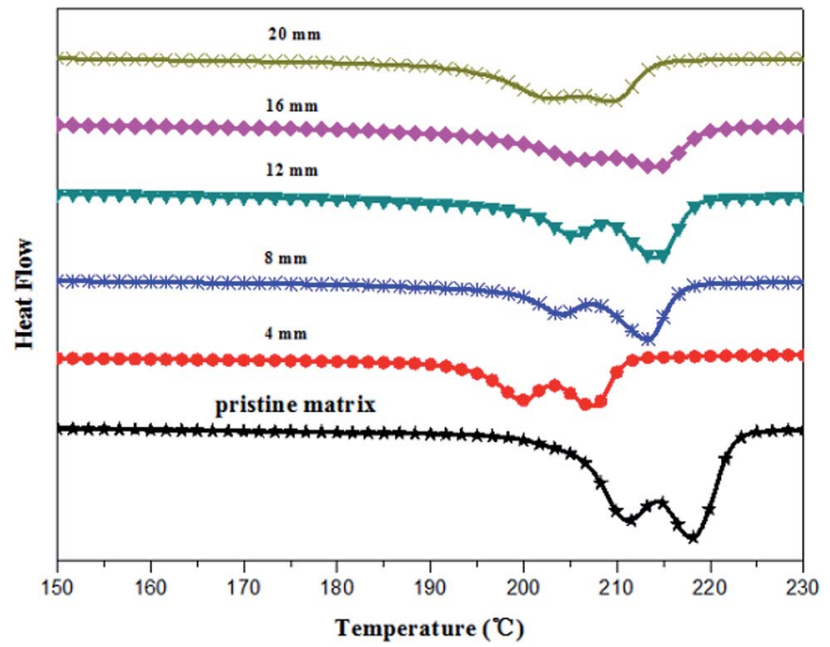

Fig. 13 DSC melting curves of the pristine matrix and LGF (40\%)/PBT composites with different lengths of the original glass fibers $(4,8,12$, 16 , and $20 \mathrm{~mm}$ ).

composites. The reason for this is that the glass fibers for LGF/ PBT composites decrease the $T_{\mathrm{c}}$ of the matrix resins. However, the $T_{\mathrm{c}}$ of LGF/PBT composites first increases and then decreases
Table 5 Crystallization and melting for the pristine matrix and LGF $(40 \%) / P B T$ composites with different lengths of the original glass fibers $(4,8,12,16$, and $20 \mathrm{~mm})$

\begin{tabular}{llllll}
\hline Samples & $T_{\mathrm{c}}\left({ }^{\circ} \mathrm{C}\right)$ & $\Delta H_{\mathrm{c}}\left(\mathrm{J} \mathrm{g}^{-1}\right)$ & $X_{\mathrm{c}}(\%)$ & $T_{\mathrm{m}} 1\left({ }^{\circ} \mathrm{C}\right)$ & $T_{\mathrm{m}} 2\left({ }^{\circ} \mathrm{C}\right)$ \\
\hline Pristine matrix & 188.73 & 20.71 & 18.53 & 211.35 & 218.06 \\
$4 \mathrm{~mm}$ & 179.25 & 14.41 & 16.29 & 199.92 & 207.45 \\
$8 \mathrm{~mm}$ & 182.87 & 14.51 & 16.40 & 203.39 & 212.19 \\
$12 \mathrm{~mm}$ & 183.91 & 16.65 & 18.82 & 205.89 & 214.84 \\
$16 \mathrm{~mm}$ & 180.58 & 16.08 & 18.17 & 205.67 & 214.55 \\
$20 \mathrm{~mm}$ & 177.92 & 15.74 & 17.79 & 202.56 & 209.67 \\
\hline
\end{tabular}

with the increase in the length of the original glass fiber for LGF/PBT composites. Furthermore, the percentage crystallinity of the pristine matrix is the highest, compared with the percentage crystallinity of the LGF/PBT composites. This is because the crystallization process for the pristine matrix resins without glass fibers have not been affected. The percentage crystallinity of the LGF/PBT composites also firstly increases and then slightly decreases with length of the original glass fibers increase in the LGF/PBT composites. When the length of the residual glass fibers for LGF/PBT composites increases, the ability of hindering the arrangement's integrity for the matrix resins segment improves in the LGF/PBT composites. The crystallization process of the matrix resins was disrupted in the LGF/PBT composites. But, $T_{\mathrm{c}}$ and percentage crystallinity of LGF/PBT composites show no significant change.

From the melting curves of the pristine matrix and LGF/PBT composites shown in Fig. 13, it can be seen that all the melting curves of the pristine matrix and LGF/PBT composites with different lengths of the original glass fibers $(4,8,12,16$ and 20 $\mathrm{mm}$ ) exhibit two melting peaks. The origin of these peaks has been ascribed to the presence of different morphologies and simultaneous melting and reorganization of the crystallites. ${ }^{31}$ The melting point of the LGF/PBT composites also firstly increases and then slightly decreases with the increase of original lengths of the glass fibers of LGF/PBT composites. This can be because the glass fibers that appear in the LGF/TPU/PBT/ PTW composites hinders the molecular motions of the matrix resins and enhance the rigidness of the LGF/PBT composites.

\subsection{TGA analysis and LOI of the LGF/PBT composites}

The thermal stability of the pristine matrix and LGF (40\%)/PBT composites was investigated using TGA, and the decomposition temperature of $5 \%$ mass loss, $10 \%$ mass loss of the pristine matrix and LGF (40\%)/PBT composites was expressed by $T_{5 \%}$ and $T_{10 \%}$, respectively. Fig. 14 shows the TG curves of thermal decomposition of the pristine matrix and LGF (40\%)/PBT composites. The TG data of the pristine matrix and LGF (40\%)/PBT composites are displayed in Table 6. From Fig. 14, it can be seen that there are two steps of decomposition in the thermal analysis curve of the pristine matrix and LGF (40\%)/PBT composites. The first process (from $300{ }^{\circ} \mathrm{C}$ to $400{ }^{\circ} \mathrm{C}$ ) resulted in the flexibilizer decomposition for the pristine matrix and LGF (40\%)/PBT composites, whereas the second thermal decomposition step after $400{ }^{\circ} \mathrm{C}$ was attributed to the mass loss of PBT for the pristine matrix and LGF (40\%)/PBT composites. 


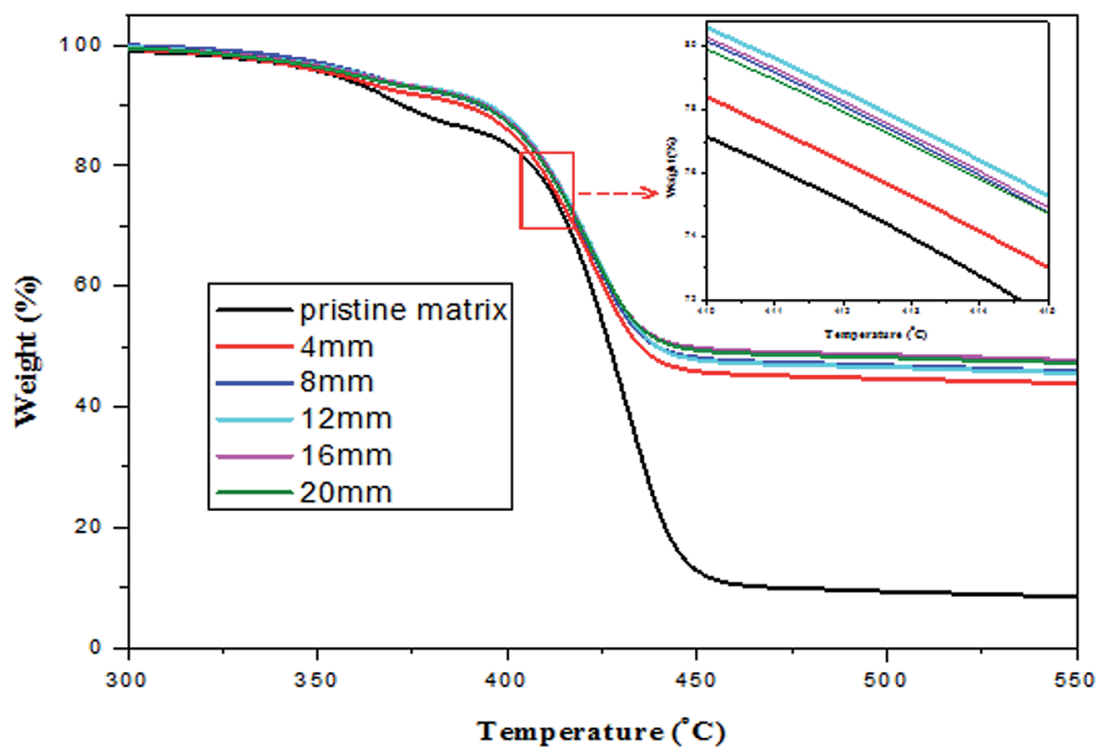

Fig. 14 TG curves of thermal decomposition of the pristine matrix and LGF (40\%)/PBT composites with different lengths of the original glass fibers $(4,8,12,16$, and $20 \mathrm{~mm})$.

Table 6 TG and LOI data of the pristine matrix and LGF (40\%)/PBT composites with different lengths of the original glass fibers $(4,8,12$, 16 , and $20 \mathrm{~mm}$ )

\begin{tabular}{llll}
\hline Samples & $T_{5 \%}\left({ }^{\circ} \mathrm{C}\right)$ & $T_{10 \%}\left({ }^{\circ} \mathrm{C}\right)$ & LOI $(\%)$ \\
\hline Pristine matrix & 354.34 & 372.42 & 21.35 \\
$4 \mathrm{~mm}$ & 354.98 & 388.72 & 21.04 \\
$8 \mathrm{~mm}$ & 363.27 & 393.15 & 21.31 \\
$12 \mathrm{~mm}$ & 363.85 & 395.14 & 21.29 \\
$16 \mathrm{~mm}$ & 361.63 & 393.95 & 21.47 \\
$20 \mathrm{~mm}$ & 359.91 & 392.14 & 21.26 \\
\hline
\end{tabular}

This observation is in accordance with other reported results. ${ }^{21,32,33}$ As shown in Fig. 14, TG curves of LGF/PBT composites firstly shift to higher temperatures and then shift to low temperatures with the increase in the length of the original glass fibers. Table 6 shows that the $T_{5 \%}$ and $T_{10 \%}$ of the pristine matrix and LGF $(40 \%) / \mathrm{PBT}$ composites firstly increase and then decrease. When length of the original glass fibers is $12 \mathrm{~mm}$, the $T_{5 \%}$ and $T_{10 \%}$ of LGF (40\%)/PBT composites $(12 \mathrm{~mm})$ are the highest. These results indicate that the thermal stability of the pristine matrix and LGF (40\%)/PBT composites firstly increases and then decreases with increase in the length of the original glass fibers.

The LOI test is usually used to evaluate the combustion behavior of the reinforced thermoplastic composites. Table 6 shows the LOI data of the pristine matrix and LGF (40\%)/PBT composites with different lengths of the original glass fibers $(4,8,12,16$, and $20 \mathrm{~mm})$. From Table 6 , the LOI values of the pristine matrix and LGF (40\%)/PBT composites with different lengths of the original glass fibers $(4,8,12,16$, and $20 \mathrm{~mm})$ are about 21, which indicates the effect of the lengths of the original glass fibers on the combustion behavior of LGF/PBT composites is not obvious.
Table 7 Mechanical properties of the pristine matrix and LGF (40\%)/ PBT composites with different lengths of the original glass fibers $(4,8$, 12,16 , and $20 \mathrm{~mm}$ )

\begin{tabular}{|c|c|c|c|c|}
\hline Samples & $\begin{array}{l}\text { Tensile } \\
\text { strength } \\
(\mathrm{MPa})\end{array}$ & $\begin{array}{l}\text { Flexural } \\
\text { strength } \\
(\mathrm{MPa})\end{array}$ & $\begin{array}{l}\text { Flexural } \\
\text { modulus } \\
(\mathrm{MPa})\end{array}$ & $\begin{array}{l}\text { Notched Izod } \\
\text { impact strength } \\
\left(\mathrm{kJ} \mathrm{m}^{-2}\right)\end{array}$ \\
\hline Pristine matrix & 43.38 & 64.51 & 1638.26 & 3.23 \\
\hline $4 \mathrm{~mm}$ & 146.89 & 208.41 & 9892.19 & 20.31 \\
\hline $8 \mathrm{~mm}$ & 149.67 & 210.43 & 11097.92 & 21.86 \\
\hline $12 \mathrm{~mm}$ & 158.46 & 233.31 & 11501.64 & 26.68 \\
\hline $16 \mathrm{~mm}$ & 142.12 & 224.53 & 11399.29 & 22.39 \\
\hline $20 \mathrm{~mm}$ & 141.56 & 209.83 & 10680.16 & 19.87 \\
\hline
\end{tabular}

\subsection{Mechanical properties}

Table 7 shows the mechanical properties of the pristine matrix and LGF/PBT composites with different lengths of the original glass fibers $(4,8,12,16$ and $20 \mathrm{~mm})$. Form Table 7 , when the glass fiber fills the pristine matrix, the mechanical properties of the LGF/PBT composites greatly improve, compared with the pristine matrix. Furthermore, the tensile strength, notched Izod impact strength, flexural strength and modulus of the LGF/PBT composites with the length of the original glass fiber $(4 \mathrm{~mm})$ were increased by $235.36 \%, 534.68 \%, 223.06 \%$ and $503.82 \%$ respectively, compared with that of the pristine matrix without the glass fiber. This indicates that the LGF have an obvious enhancement effect on the pristine matrix. Furthermore, the tensile strength, notched Izod impact strength, flexural strength and modulus of the LGF/PBT composites firstly increase and then decrease with increase of the length of the original glass fibers. The results shown in Table 7 indicate that the residual glass fiber length increases with the increase in length of the original glass fiber for LGF/PBT composites. This improves the mechanical properties of LGF/PBT composites. From Fig. 3a-c, 
and 4 the glass fibers of the LGF/PBT composites (4, 8 and 12 $\mathrm{mm}$ ) are homogeneously dispersed and there is no phenomenon of reunion in the matrix resins. This indicates that outstanding mechanical properties of LGF/PBT composites $(4,8$ and $12 \mathrm{~mm}$ ) were obtained. However, from Fig. 3d and e, and 4 it can be seen that the glass fibers of the LGF/PBT composites (16 and $20 \mathrm{~mm}$ ) were unevenly dispersed and they show the phenomenon of reunion in the matrix resins. This leads to the bad mechanical properties of the LGF/PBT composites (16 and $20 \mathrm{~mm}$ ). The mechanical properties of LGF/PBT composites, therefore, firstly increase and then decrease with increase of the length of the original glass fibers of LGF/PBT composites. Furthermore, the tensile strength, notched Izod impact strength flexural strength and modulus of the LGF/PBT composites with the length of the original glass fibers $(12$ $\mathrm{mm}$ ) were increased by $7.87 \%, 31.36 \%, 11.95 \%$ and $16.26 \%$ respectively, compared with that of the LGF/PBT composites with the length of the original glass fibers $(4 \mathrm{~mm})$.

\section{Conclusions}

The paper reports the effect of fiber length and distribution on the rheological characterization, dynamic mechanical, thermal and mechanical properties of the pristine matrix and LGF/PBT composites. The results showed that the length of the residual glass fibers of the LGF/PBT composites increase as the length of the original glass fiber increases. However, the SEM results indicate that when the length of the original glass fibers is 16 and $20 \mathrm{~mm}$, the glass fibers of the LGF/PBT composites show the phenomenon of reunion in the matrix resins. The complex viscosities, $G^{\prime}$ and $G^{\prime \prime}$ of the pristine matrix and LGF/PBT composites increased gradually. The $\tan \delta$ curves for the pristine matrix and LGF/PBT composites show a peak when the length of the original glass fibers increases. This is because the ability of restricting the chain segment for the matrix resins can be stronger with the increase in the length of the original glass fiber, which causes the terminal relaxation time. DMA results show that the storage modulus and loss modulus of the pristine matrix and LGF/PBT composites firstly increase and then decrease with the increase of the length of the original glass fiber. The difference between the DMA results and the rheological measurements can be because the test conditions and state used for DMA and ARES techniques are different. The $T_{\mathrm{g}}$ of the pristine matrix and LGF/PBT composites shifted to the higher temperature with increasing test frequencies. The $T_{\mathrm{c}}$, percentage crystallinity and melting point of the LGF/PBT composites firstly increases and then decreases with the increase of the length of the original glass fibers. The mechanical properties of LGF/PBT composites, therefore, firstly increase and then decrease with the increase of the length of the original glass fiber of LGF/PBT composites.

\section{Acknowledgements}

The authors would like to acknowledge the financial support from Natural Science Foundation of China (Grants: 51463006, 51663006), Guizhou Province Science and Technology Plan Projects (Grants: [2015] 7708, [2016] 4526, [2016] 4535, [2016]
2812), Guizhou Province High Level Innovative Talents Training Project (Grant: [2016] 5630), Guizhou Province Project Education Fund (Grant: [2015] 359), Special Funds of Guizhou Province Major Projects (Contract Grant number: [2015] 6005).

\section{References}

$1 \mathrm{~J}$. L. Thomason, The influence of fibre length and concentration on the properties of glass fibre reinforced polypropylene 5 . Injection moulded long and short fibre PP, Composites, Part A, 2002, 33, 1641-1652.

$2 \mathrm{~J}$. L. Thomason, The influence of fibre length and concentration on the properties of glass fibre reinforced polypropylene. 6 . The properties of injection moulded long fibre PP at high fibre content, Composites, Part A, 2005, 36, 995-1003.

3 J. L. Thomason, The influence of fibre length and concentration on the properties of glass fibre reinforced polypropylene:7. Interface strength and fibre strain in injection moulded long fibre PP at high fibre content, Composites, Part A, 2007, 38, 210-216.

4 E. Lafranche, P. Krawczak, J. P. Ciolczyk, et al., Injection moulding of long glass fiber reinforced polyamide 66: processing conditions/microstructure/flexural properties relationship, Adv. Polym. Technol., 2005, 24, 114-131.

5 D. Teixeira, M. Giovanela, L. B. Gonella and J. S. Crespo, Influence of injection molding on the flexural strength and surface quality of long glass fiber-reinforced polyamide 6.6 composites, Mater. Des., 2015, 85, 695-706.

$6 \mathrm{~J}$. H. Phelps, A. I. Abd El-Rahman, V. Kunc, et al., A model for fiber length attrition in injection-molded long-fiber composites, Composites, Part A, 2013, 51, 11-21.

7 W. Yan, K. Han, L. Qin, et al., Study on long fiber-reinforced thermoplastic composites prepared by in situ solidstate polycondensation, J. Appl. Polym. Sci., 2004, 91, 3959-3965.

8 D. H. Zhang, M. He, S. H. Qin and J. Yu, Influences of poly(ethylene-butylacrylate-glycidyl methacrylate copolymer) on rheology characterization, morphology, dynamic mechanical, thermal, and mechanical properties of long glass fibers reinforced. Poly(butylene terephthalate) composites, Polym. Compos., 2016, 11, 1-10.

9 T. Vu-Khanh, J. Denault, P. Habib and A. Low, The effects of injection molding on the mechanical behavior of long-fiber reinforced PBT/PET blends, Compos. Sci. Technol., 1991, 40, 423-435.

10 T. P. Skourlis, K. Pochiraju, C. Chassapis and S. Manoochehri, Structure-modulus relationships for injection-molded long fiber-reinforced polyphthalamides, Composites, Part B, 1998, 29, 309-320.

11 W. Hale, H. Keskkula and D. R. Paul, Fracture behavior of PBT-ABS blends compatibilized by methyl methacrylateglycidyl methacrylate-ethyl acrylate terpolymers, Polymer, 1999, 40, 3353-3365.

12 P. J. Hine, H. R. Lusti and A. A. Gusev, Numerical simulation of the effects of volume fraction, aspect ratio and fibre length distribution on the elastic and thermoelastic properties of 
short fibre composites, Compos. Sci. Technol., 2002, 62, 14451453.

13 Y. H. Tan, X. D. Wang and D. Z. Wu, Preparation, microstructures, and properties of long-glass-fiber-reinforced thermoplastic composites based on polycarbonate/ poly(butylenes terephthalate) alloys, J. Reinf. Plast. Compos., 2015, 34, 1804-1820.

$14 \mathrm{~S} . \mathrm{Fu}$ and B. Lauke, Effects of fiber length and fiber orientation distributions on the tensile strength of shortfiber-reinforced polymers, Compos. Sci. Technol., 1996, 56, 1179-1190.

15 D. Notta-cuvier, R. Lauro and B. Bennani, Modelling of progressive fibre/matrix debonding in short-fibre reinforced composites up to failure, Int. J. Solids Struct., 2015, 66, 140150.

16 Z. A. Mohd Ishak, A. Ariffin and R. Senawi, Effects of hygrothermal aging and a silane coupling agent on the tensile properties of injection molded short glass fiber reinforced poly(butylene terephthalate) composites, Eur. Polym. J., 2001, 37, 1635-1647.

$17 \mathrm{~S}$. Hashemi, Temperature, strain rate and weldine effects on strength and micromechanical parameters of short glass fibre reinforced polybutylene terephthalate (PBT), Polym. Test., 2011, 30, 801-810.

18 P. M. Wood-Adams and J. M. Dealy, Effect of molecular structure on the linear viscoelastic behavior of polyethylene, Macromolecules, 2000, 33, 7489-7499.

19 C. G. Franco, S. Srinivas and D. J. Lohse, Similarities between gelation and long chain branching viscoelastic behavior, Macromolecules, 2001, 34, 3115-3117.

20 C. G. Robertson, C. G. Franco and S. Srinivas, Extent of branching from linear viscoelasticity of long-chainbranched polymers, J. Polym. Sci., Part B: Polym. Phys., 2004, 42, 1671-1684.

21 D. H. Zhang, M. He, S. H. Qin and J. Yu, Rheology characterization, dynamic mechanical, thermal, and mechanical properties of LGF/TPU/PBT/PTW composites, Polym. Compos., 2016, 21, 1-13.

22 D. Graebling, Synthesis of branched polypropylene by a reactive extrusion process, Macromolecules, 2002, 35, 4602-4610.
23 J. B. Guo, D. H. Zhang, H. J. Shao, K. Z. Zhang and B. Wu, Preparation and properties of LGF/ER/TPU/PMMA composites, Sci. Eng. Compos. Mater., 2015, 22, 17-23.

24 W. He, T. Xing, G. X. Liao, W. Lin, F. Deng and X. G. Jian, Dynamic mechanical properties of PPESK/silica hybrid materials, Polym.-Plast. Technol. Eng., 2009, 48, 164-169.

25 X. Liu, H. Huang, Z. Y. Xie, Y. Zhang, Y. X. Zhang, K. Sun and L. M. Min, EPDM/polyamide TPV compatibilized by chlorinatedpolyethylene, Polym. Test., 2003, 22, 9-16.

26 B. Nandan, L. D. Kandpal and G. N. Mathur, Glass transition behavior of poly(ether ether ketone)/poly(aryl ether sulphone) blends: dynamic mechanical and dielectric relaxation studies, Polymer, 2003, 44, 1267-1279.

27 B. Redondo-Foj, M. Carsí, P. Ortiz-Serna, M. J. Sanchis, F. García and J. M. García, Relaxational study of poly(vinylpyrrolidone-co-butyl acrylate) membrane by dielectric and dynamic mechanical spectroscopy, J. Phys. D: Appl. Phys., 2013, 46, 1-13.

28 D. H. Zhang, M. He, J. B. Guo and K. Z. Zhang, Mechanical properties, morphology and dynamic mechanical properties of LGF/TPU/SAN composites, Fibers Polym., 2014, 15, 794-799.

29 M. R. Aghjeha, H. A. Khonakdar and S. H. Jafaria, Application of mean-field theory in PP/EVA blends by focusing on dynamic mechanical properties in correlation with miscibility analysis, Composites, Part B, 2015, 79, 74-82.

30 G. Li, P. Lee-Sullivan and R. W. Thring, Determination of activation energy for glass transition of an epoxy adhesive using dynamic mechanical analysis, J. Therm. Anal. Calorim., 2000, 60, 377-390.

31 H. Yang, M. Lai, W. Liu, C. Sun and J. Liu, Morphology and thermal and mechanical properties of PBT/HIPS and PBT/ HIPS-G-GMA blends, J. Appl. Polym. Sci., 2002, 85, 26002608.

32 Y. A. El-Shekeil, S. M. Sapuan, K. Abdan and E. S. Zainudin, Influence of fiber content on the mechanical and thermal properties of Kenaf fiber reinforced thermoplastic polyurethane composites, Mater. Des., 2012, 40, 299-303.

33 G. Botelho, A. Queiros and P. Gijsman, Studies on thermal and thermo-oxidative degradation of poly(ethylene terephthalate) and poly(butylene terephthalate), Polym. Degrad. Stab., 2001, 73, 431-435. 